\title{
Adjuvant Sorafenib for Renal Cell Carcinoma a clacosore Intermediate or High Risk of Relapse: Results From the SORCE Randomized Phase III Intergroup Trial
}

Tim Eisen, MB BChir, PhD; Eleni Frangou, MSc (Res)²; Bhavna Oza, MBBS²; Alastair W.S. Ritchie, MD $^{2}$; Benjamin Smith, BSc ${ }^{2}$; Rick Kaplan, MD²; lan D. Davis, MBBS, PhD ${ }^{3}$; Martin R. Stockler, MBBS, $\mathrm{MSc}^{4}$; Laurence Albiges, MD, PhD ${ }^{5}$; Bernard Escudier, MD $^{5}$; James Larkin, $\mathrm{PhD}^{6}$; Axel Bex, MD, PhD ${ }^{7,8}$; Steven Joniau, MD, $\mathrm{PhD}^{9}$; Barry Hancock, $\mathrm{MD}^{10}$; Gregers G. Hermann, MD, DMSc ${ }^{11}$; Joaquim Bellmunt, MD, PhD ${ }^{12}$; Elizabeth Hodgkinson, BPharm, MSc ${ }^{13}$; Grant D. Stewart, MBChB ${ }^{14}$; Jim Barber, DM $^{15}$; Janet Brown, MD ${ }^{16,17}$; Rhona McMenemin, MSc ${ }^{18}$; Paul Nathan, MBBS, MD ${ }^{19}$; Lisa M. Pickering, PhD ${ }^{6}$; Mahesh K.B. Parmar, DPhil' ${ }^{2}$ and Angela Meade, DPhil ${ }^{2}$

PURPOSE SORCE is an international, randomized, double-blind, three-arm trial of sorafenib after surgical excision of primary renal cell carcinoma (RCC) found to be at intermediate or high risk of recurrence.

PATIENTS AND METHODS We randomly assigned participants (2:3:3) to 3 years of placebo (arm A), 1 year of sorafenib followed by 2 years of placebo (arm B), or 3 years of sorafenib (arm C). The initial sorafenib dose was $400 \mathrm{mg}$ twice per day orally, amended to $400 \mathrm{mg}$ daily. The primary outcome analysis, which was revised as a result of external results, was investigator-reported disease-free survival (DFS) comparing 3 years of sorafenib versus placebo.

RESULTS Between July 2007 and April 2013, we randomly assigned 1,711 participants (430, 642, and 639 participants in arms A, B, and C, respectively). Median age was 58 years, $71 \%$ of patients were men, $84 \%$ had clear cell histology, $53 \%$ were at intermediate risk of recurrence, and $47 \%$ were at high risk of recurrence. We observed no differences in DFS or overall survival in all randomly assigned patients, patients with high risk of recurrence, or patients with clear cell RCC only. Median DFS was not reached for 3 years of sorafenib or for placebo (hazard ratio, 1.01; $95 \% \mathrm{Cl}, 0.83$ to $1.23 ; P=.95$ ). We observed nonproportional hazards; the restricted mean survival time (RMST) was 6.81 years for 3 years of sorafenib and 6.82 years for placebo (RMST difference, 0.01 year; $95 \% \mathrm{Cl},-0.49$ to 0.48 year; $P=.99$ ). Despite offering treatment adaptations, more than half of participants stopped treatment by 12 months. Grade 3 hand-foot skin reaction was reported in $24 \%$ of participants on sorafenib.

CONCLUSION Sorafenib should not be used as adjuvant therapy for RCC. Active surveillance remains the standard of care for patients at intermediate or high risk of recurrence after nephrectomy and is the appropriate control of our current international adjuvant RCC trial, RAMPART.

ASSOCIATED

CONTENT

Appendix

Protocol

Author affiliations and support information (if applicable) appear at the end of this article.

Accepted on August 25,2020 and published at ascopubs.org/journal/ jco on October 14, 2020: DOI https://doi. org/10.1200/JCO.20. 01800

J Clin Oncol 38. $\odot 2020$ by American Society of Clinical Oncology

\section{INTRODUCTION}

In 2018, > 400,000 new renal cell carcinomas (RCCs) were diagnosed, and 175,098 deaths were attributed to RCC worldwide. ${ }^{1}$ Two thirds of patients with RCC present with disease confined to the kidney, which is potentially curable by surgery alone. Scoring systems, such as the Leibovich score, use clinical factors to categorize patients according to their risk of relapse or death. Patients with intermediate- or high-risk RCC after surgical resection are at significant risk of relapse and death. The 5-year relapse rate for these patients is 30\%-40\%; 5-year survival has been reported at $74.8 \%$, which declines steeply to $16 \%$ once patients develop metastatic disease. ${ }^{2}$
Effective treatments to reduce the risk of recurrence or cancer death in patients with locoregional RCC remain an unmet clinical need. Adjuvant strategies in RCC, including cytokines, radiotherapy, and hormone therapy, have been explored with no success. ${ }^{3}$ Oral tyrosine kinase inhibitors (TKIs) targeting the vascular endothelial growth factor (VEGF) receptor, including sunitinib, sorafenib, and pazopanib, are effective in metastatic RCC, which supported their evaluation in the adjuvant setting and our decision to investigate the use of the multitargeted TKI sorafenib in the SORCE trial. ${ }^{4-6}$

Four randomized controlled trials investigating TKIs in the adjuvant RCC setting have reported to date. 


\section{CONTEXT}

\section{Key Objective}

We designed SORCE to investigate the role of sorafenib in prolonging disease-free survival (DFS) and overall survival (OS) in patients with resected renal cell cancer (RCC) found to be at immediate or high-risk of recurrence.

\section{Knowledge Generated}

We observed no benefit for DFS or OS after up to 3 years of sorafenib treatment. Moreover, grade $\geq 3$ toxicities were experienced by six in 10 patients who received treatment. A reduction in the initial starting dose improved compliance, but despite offering treatment adaptations, over half of participants stopped treatment by 12 months.

\section{Relevance}

SORCE results are definitive; sorafenib should not be used as adjuvant therapy for patients with resected RCC. SORCE is the fifth and final trial to report on the role of tyrosine kinase inhibitor therapy as an adjuvant treatment of RCC. SORCE results confirm that active surveillance remains the global standard of care for patients at intermediate or high risk of recurrence after nephrectomy.

S-TRAC (ClinicalTrials.gov identifier: NCT00375674), ASSURE (ClinicalTrials.gov identifier: NCT00326898), and PROTECT (ClinicalTrials.gov identifier: NCT01235962) explored 1 year of adjuvant TKI therapy, whereas ATLAS (ClinicalTrials.gov identifier: NCT01599754) explored up to 3 years of TKI therapy. ${ }^{7-10}$ In S-TRAC, a modest diseasefree survival (DFS) benefit with 1 year of sunitinib was observed based on blinded independent central review (hazard ratio [HR], 0.76; $95 \% \mathrm{Cl}, 0.59$ to $0.98 ; P=.03$ ). ${ }^{10,11}$ On the basis of these results, the US Food and Drug Administration approved sunitinib for the adjuvant treatment of patients with RCC at high risk of recurrence. The European Medicines Agency did not approve sunitinib use in this setting. Therefore, these results have not been universally practice changing, and the international standard of care for resected RCC remains nephrectomy followed by active surveillance. ${ }^{12,13}$

The particular value of SORCE is to settle the question of adjuvant TKI therapy. Here, we report findings from the primary analysis of SORCE, comparing participants who were randomly assigned to receive 3 years of sorafenib with those who were randomly assigned to receive placebo. We also report the findings of our analyses of participants randomly assigned to 1 year of sorafenib versus those assigned to placebo.

\section{PATIENTS AND METHODS}

\section{Study Design}

SORCE (ClinicalTrials.gov identifier: NCT00492258) is an international, double-blind, three-arm, randomized, phase III trial evaluating different durations of adjuvant sorafenib compared with placebo.

\section{Participants}

Eligible participants had histologically proven, completely resected, clear cell or non-clear cell RCC at intermediate (score, 3-5) or high risk (score, 6-11) of relapse as per the Leibovich risk model. ${ }^{14}$ The Leibovich score is a validated scoring model incorporating TNM stage, tumor size, nuclear grade, and presence of tumor necrosis. Details on the features and calculation of the Leibovich score can be found in Appendix Table A1 (online only). Patients with resected metastatic (M1) disease were not eligible.

Participants were enrolled within 13 weeks of nephrectomy, were $\geq 18$ years old, had WHO performance status of 0 or 1 , and demonstrated adequate bone marrow, renal, hepatic, and pancreatic function. All participants provided written informed consent.

\section{Randomization and Masking}

Participants were randomly assigned (2:3:3) using stratified blocks to receive 3 years of placebo (arm A), 1 year of sorafenib followed by 2 years of placebo (arm B), or 3 years of sorafenib (arm C). SORCE was a double-blind trial. Participants were stratified by country and Leibovich risk group.

\section{Treatment and Follow-Up}

The initial starting dose of sorafenib was 400 mg twice daily, with permitted dose reductions in the event of toxicity, first to $400 \mathrm{mg}$ once daily and then to $400 \mathrm{mg}$ on alternate days. In January 2009, we amended the starting dose to $400 \mathrm{mg}$ once daily to address a higher than expected discontinuation rate (protocol version 1.4, November 2008). After 3 weeks of treatment, the dose could be maintained or escalated to the full dose of $400 \mathrm{mg}$ twice daily at clinician discretion. Pill counts were performed at assessment visits to allow assessment of dosing compliance.

Patients were assessed at weeks 3 and 6 after the start of their treatment to identify and treat any early toxicities and every 3 months for adverse events (AEs). Imaging alternated between chest $\mathrm{x}$-ray and contrast computed tomography (CT) of the chest and abdomen every 3 months 
during treatment. After completion of treatment, participants had chest $x$-rays only every 6 months until year 5 and then annually until year 10 . Recurrence was assessed by local investigators.

\section{Outcome Measures}

The primary outcome measure is DFS, defined as the interval from random assignment to first evidence of local recurrence, distant metastases, or death from RCC. Secondary outcomes included overall survival (OS), defined as the time from randomization to death from any cause; metastasis-free survival (MFS), defined as the time from randomization to first evidence of metastases or death from RCC; RCC-specific survival time; and safety (using CTCAE v3.0). Participants alive and without an event at the time of each time-to-event analysis were censored on the date they were last seen on the trial.

\section{Changing the Primary Research Question}

The original primary objective in SORCE was to determine whether at least 1 year of treatment with sorafenib increases DFS compared with placebo (a comparison of arms $B$ and $C$ combined $v$ arm A). Primary results from the ASSURE and S-TRAC trials were reported after SORCE closed to recruitment. Considering these results and without knowledge of the developing outcome data, the SORCE Trial Management Group (TMG) and the independent members of the executive oversight Trial Steering Committee approved a change to the primary analysis of SORCE. These changes are documented in our protocol and statistical analysis plan and were all agreed on before database lock. ${ }^{15}$

The revised primary analysis objectives were as follows: Does up to 3 years of treatment with sorafenib increase DFS compared with placebo (a comparison of arm $C v$ arm A), and if so, does up to 1 year of sorafenib (arm B) increase DFS compared with placebo (arm A)? A closed testing procedure was used for the second question, which naturally preserves the type I error. If the analysis of the first objective did not show statistical significance, results for the second objective would still be presented for completeness, although no statistical inferences can be drawn.

\section{Study Oversight}

The trial was approved by national regulatory and ethical committees in each participating country and was conducted in accordance to the principles of Good Clinical Practice, the Declaration of Helsinki, and all applicable regulatory requirements and laws. An Independent Data Monitoring Committee (IDMC) reviewed participant safety on a regular basis and efficacy data at prespecified time points. An executive Trial Steering Committee received trial reports on at least an annual basis.

\section{Sample Size}

The sample size for SORCE was based on the original primary research question. It was calculated using the ART software assuming an HR of 0.75 between arm A and arms $\mathrm{B}$ and $\mathrm{C}$ combined. ${ }^{16}$ We assumed conservatively that the 2 additional years of sorafenib in arm $C$ would not increase DFS compared with arm B. DFS at 3 years for participants in arm A, obtained from Leibovich et $\mathrm{al}^{14}$ and restricted to the intermediate and poor prognostic groups, was estimated to be $63.5 \%$. To demonstrate a clinically important improvement in 3-year DFS from 63.5\% to 71\% (HR, 0.75) with sorafenib, using a log-rank test with $90 \%$ power and $5 \%$ two-sided significance level, required 608 DFS events, 179 of which would be in arm A. The total sample size target was 1,656 participants (414 participants in arm A and 621 in each of arms $B$ and $C$ ).

Because recruitment was complete at the time of changing the primary research questions, the sample size was not recalculated. The target number of control arm events remained unchanged at 179 DFS events. With this number of events in the control arm and with all other assumptions unchanged, the study had $86 \%$ power to detect an HR of 0.75 at the $5 \%$ two-sided significance level. Two subgroup analyses were prepowered before analysis (Appendix, online only) —DFS in participants with a high-risk Leibovich score (score, 6-11) and in participants with clear cell histology.

\section{Interim Assessment by the IDMC}

Two planned interim efficacy analyses were performed after approximately 200 and 400 of the planned events had occurred using a stringent two-sided significance level of $P=.001$ at each interim analysis (Peto boundary). The IDMC requested one additional efficacy analysis, which was carried out after approximately 500 events. On each occasion, the IDMC recommended that the trial continue as planned. The final analysis was performed with no adjustment for multiple testing.

\section{Statistical Analysis Plan}

A final statistical analysis plan was approved before any analyses were performed. All efficacy analyses were performed on the intent-to-treat (ITT) population. Survival curves were estimated based on the Kaplan-Meier method. Cox proportional hazards models, adjusted for the stratification factors used at randomization, were fitted to the data to obtain the HR and associated Cls. The proportional hazards assumption was tested using the GrambschTherneau test based on the ranks of the failure times, using a significance level of $P=.1$ as a guide. Restricted mean survival time (RMST) was emphasized in the presence of nonproportionality, using a time horizon $\left(t^{\star}\right)$ of 10 years. ${ }^{17}$ The RMST is the area under the survival distribution from 0 to $t^{*}$ and is interpreted as the life expectancy between randomization $(t=0)$ and a particular time horizon $(t=t *) .{ }^{18}$ To estimate the survival distribution, we fitted flexible parametric models with $(3,1)$ df and adjusted for the stratification factors and time to event. All tests are presented as two sided, with 95\% Cls and relevant 


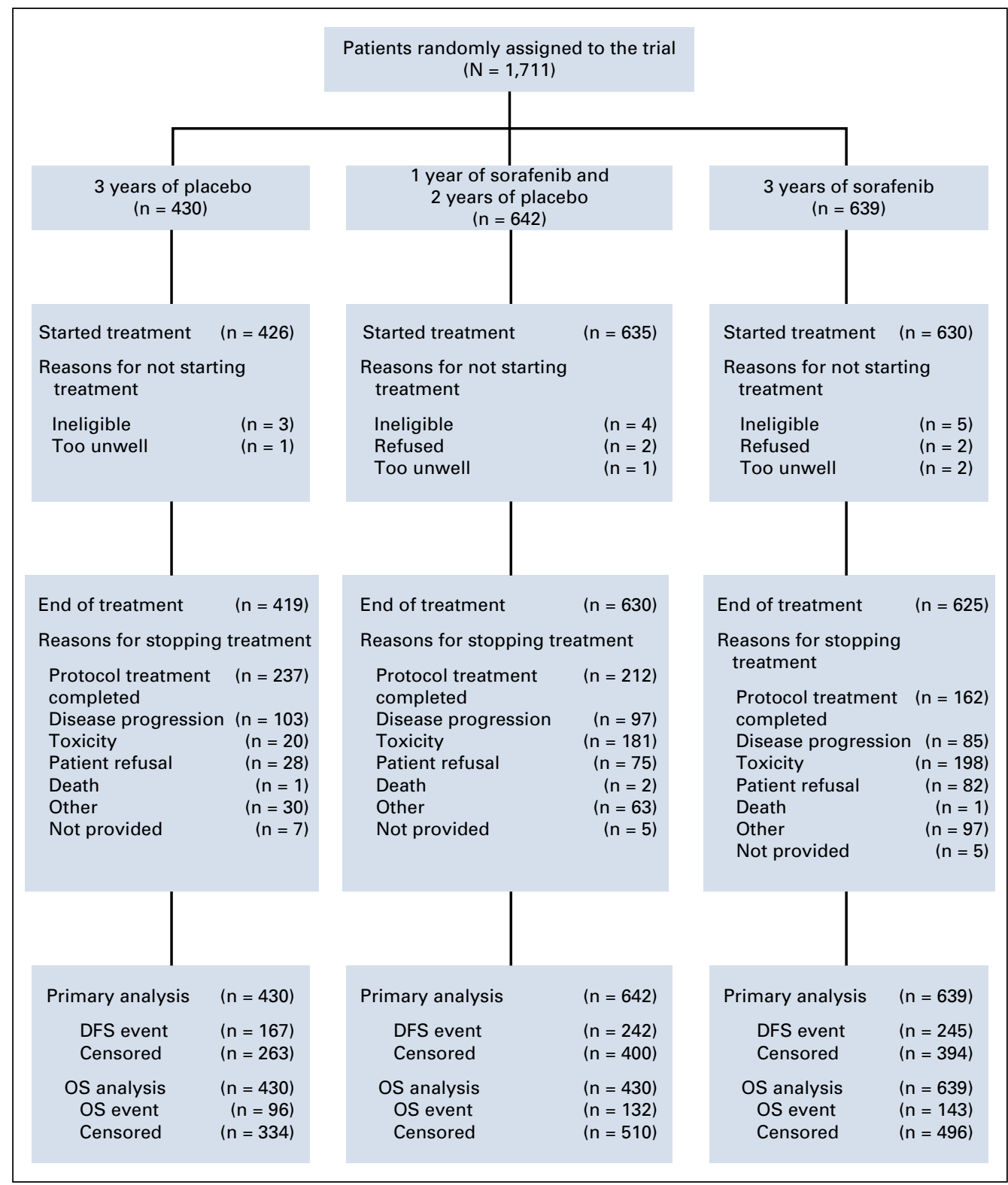

$P$ values. AE data are summarized for the safety population, defined as participants who received at least one dose of their allocated trial treatment.

\section{RESULTS}

\section{Participants}

We randomly assigned 1,711 participants from 147 sites in seven countries between July 24, 2007, and April 12, 2013; 430 participants were assigned to placebo for 3 years (arm A), 642 to sorafenib for 1 year followed by placebo for 2 years (arm B), and 639 to sorafenib for 3 years (arm C). The number of participants who did not receive any drug or placebo were five, 17 , and 26 patients in arms A, B, and C, respectively; these participants are included in the ITT analysis for primary efficacy but excluded from the safety analysis (Fig 1). Median follow-up at the time of analysis was 6.5 years (interquartile range [IQR], 4.9-8.0 years). The baseline characteristics of participants are listed in Table 1 and were well balanced across the treatment arms.

\section{DFS}

We observed no difference in DFS between patients randomly assigned to 3 years of sorafenib and those assigned to placebo (HR, 1.01; 95\% Cl, 0.82 to $1.23 ; P=.946 ; 245$ events for 3 years of sorafenib and 167 events for placebo). We observed nonproportional hazards $(P=.042)$; the RMST estimate over 10 years was 6.81 years $(95 \% \mathrm{Cl}, 6.52$ to 7.11 years) for 3 years of sorafenib and 6.82 years (95\% Cl, 6.45 to 7.18 years) for placebo (difference, 0.01 year; $P=.988)$. 
TABLE 1. Baseline Characteristics

\section{Characteristic}

3 Years of Placebo 1 Year of Sorafenib Plus 2 Years of 3 Years of Sorafenib

All Patients

$(n=430)$

Placebo $(n=642)$

$(n=639)$

$(\mathrm{N}=1,711)$

Mean age at random assignment, years (SD)

$58.43(10.35)$

$58.34(10.60)$

57. 97 (10.86)

$58.22(10.63)$

Time from RCC diagnosis to random assignment, days 84.03 (26.33)

$82.24(31.86)$

$83.23(30.65)$

83.06 (30.09)

(SD)

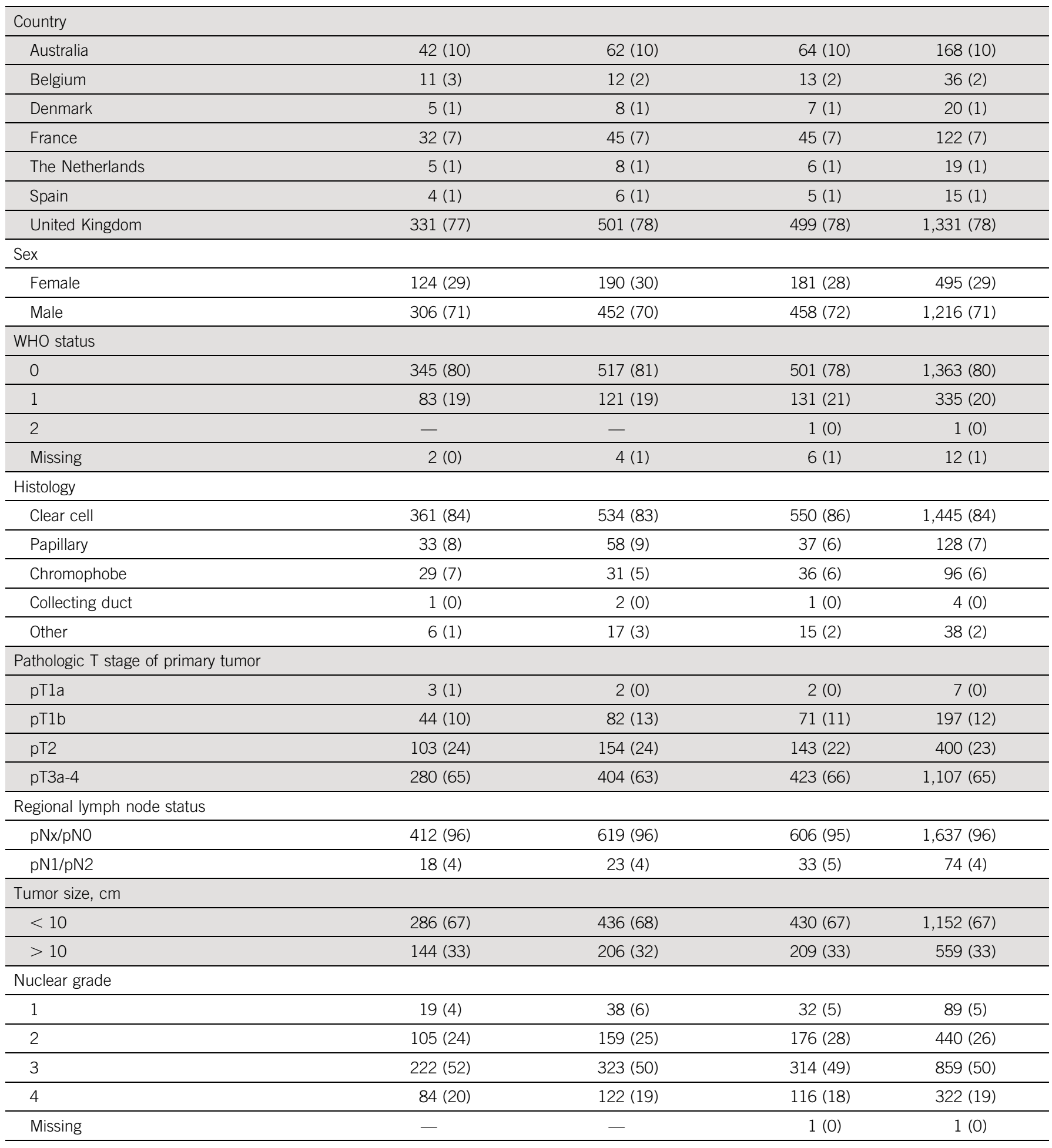

(continued on following page) 
TABLE 1. Baseline Characteristics (continued)

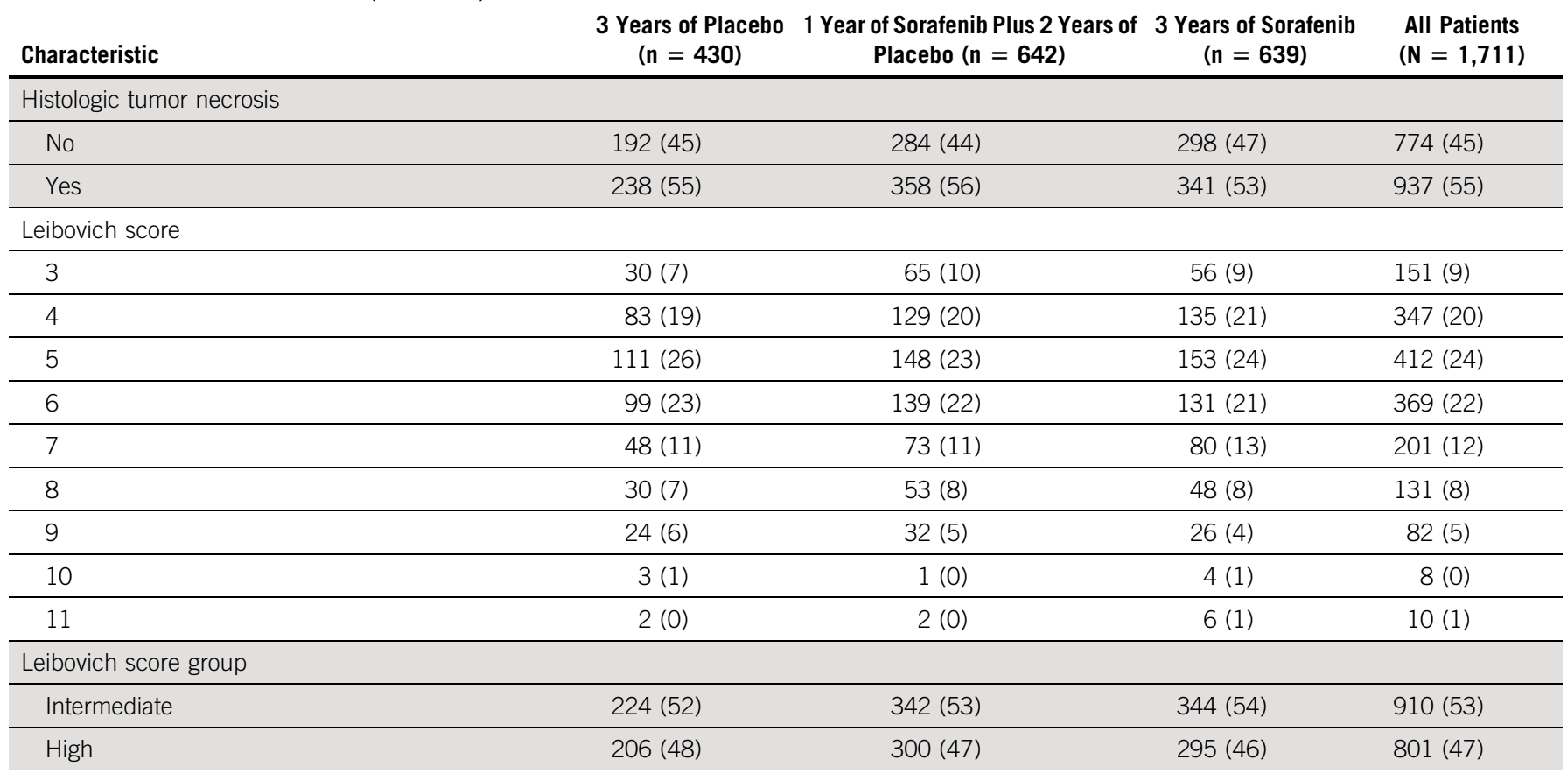

NOTE. Data presented as No. (\%), unless otherwise indicated.

Abbreviations: RCC, renal cell carcinoma; SD, standard deviation.

Comparing 1 year of sorafenib versus placebo, we also observed no difference in DFS ( $\mathrm{HR}, 0.94 ; 95 \% \mathrm{Cl}, 0.77$ to 1.14; $P=.509 ; 245$ events for 1 year of sorafenib and 167 events for placebo). Again, nonproportional hazards were evident ( $P=.001$ ). The RMST estimate over 10 years was 6.98 years $(95 \% \mathrm{Cl}, 6.70$ to 7.27 years) for 1 year of sorafenib and 6.79 years $(95 \% \mathrm{Cl}, 6.43$ to 7.16 years $)$ for placebo (difference, 0.19 year; $P=.422$ ).

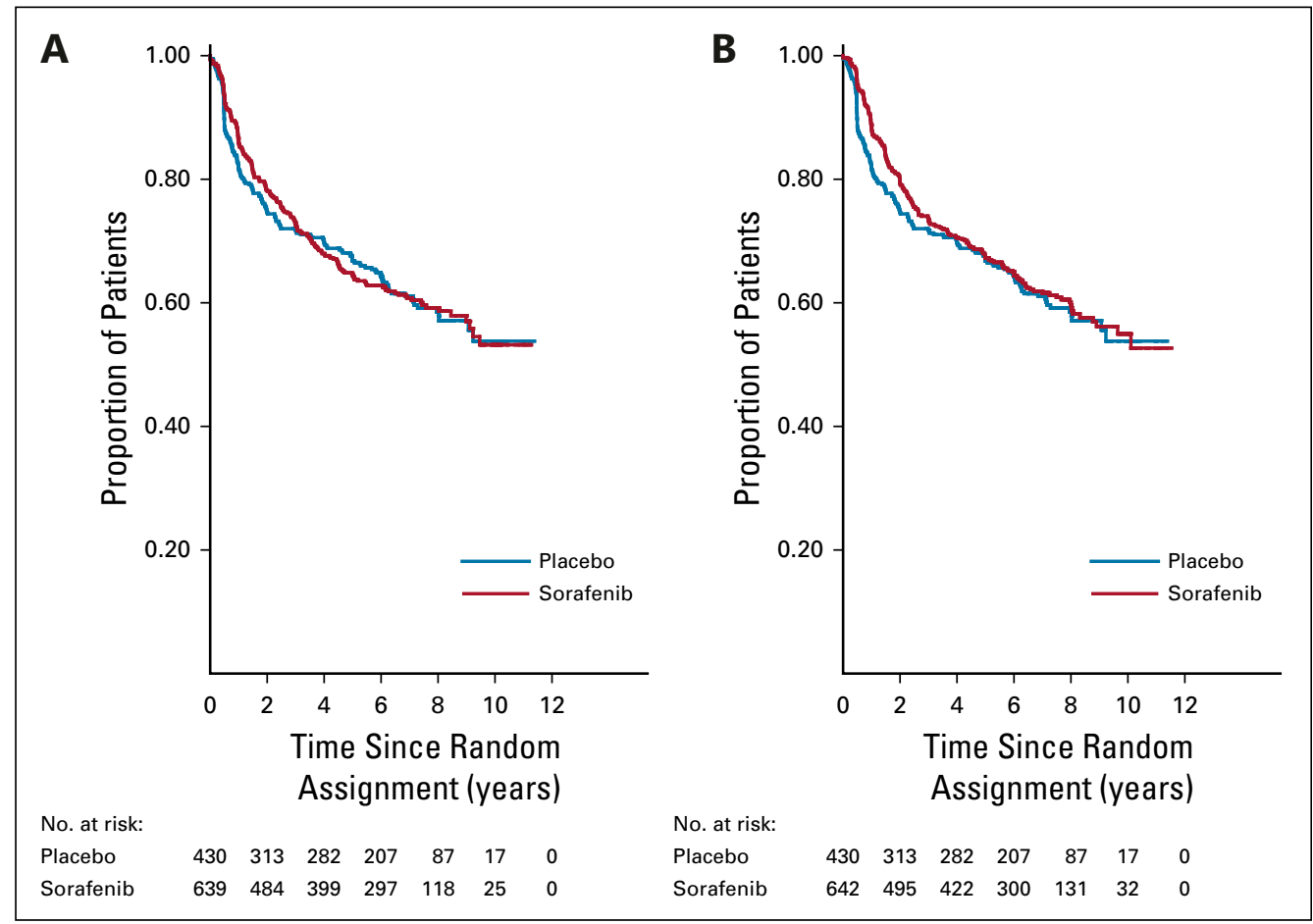

FIG 2. Disease-free survival in patients randomly assigned to (A) 3 years of sorafenib versus placebo and (B) 1 year of sorafenib versus placebo. 
TABLE 2. Cause of Death by Treatment Arm

No. of Patients

\begin{tabular}{lrrr} 
Cause of Death & Placebo & $\mathbf{1}$ Year of Sorafenib & 3 Years of Sorafenib \\
\hline Disease related & 77 & 105 & 122 \\
\hline Protocol treatment related & 0 & $1^{\text {a }}$ & 0 \\
\hline Other cause & 17 & 25 & 20 \\
\hline Missing & 2 & 1 & 1 \\
\hline Total & 96 & 132 & 143
\end{tabular}

${ }^{\text {a}}$ For more information, see Fairfax et al. ${ }^{22}$

Median DFS was not reached in any of the arms in SORCE. Ten-year DFS rate was $54 \%$ for placebo, $53 \%$ for 3 years of sorafenib and 55\% for 1 year of sorafenib (Fig 2).

\section{OS}

At the time of analysis, 371 patients had died; the causes of death are listed in Table 2 and Appendix Table A2 (online only). No difference in duration of OS was observed ( 3 years of sorafenib $v$ placebo: $\mathrm{HR}, 1.06 ; 95 \% \mathrm{Cl}, 0.82$ to 1.38 ; $P=.638 ; 1$ year of sorafenib $v$ placebo: $\mathrm{HR}, 0.92 ; 95 \% \mathrm{Cl}$, 0.71 to $1.20 ; P=.541$ ). Proportional hazards were observed, so as per our statistical analysis plan, we have not reported RMST. Ten-year OS rate was $69 \%$ for placebo, $70 \%$ for 3 years of sorafenib, and $69 \%$ for 1 year of sorafenib (Fig 3 ).

\section{Preplanned DFS Subgroup Analyses}

We observed no difference in DFS for either 3 years or 1 year of sorafenib compared with placebo in our two preplanned and prepowered analyses in participants with Leibovich high-risk disease and in those with clear cell RCC or in our modified DFS population (Appendix Tables A3 and $A 4$ and Figs $A 1$ and $A 2$, online only).

\section{AEs and Safety}

In total, 1,663 (97\%) of 1,711 patients started treatment and are included in the safety analysis (placebo, $n=425$; 1 year of sorafenib, $n=625$; and 3 years of sorafenib, $n=613$ ). Almost all patients in the safety population had at least one AE of any grade (99\%). At least one grade $\geq 3$ AE was reported by 366 patients (58.6\%) receiving 1 year of sorafenib, 392 patients (63.9\%) receiving 3 years of sorafenib, and 124 patients (29.2\%) receiving placebo. The proportion of patients who experienced at least one serious AE (SAE) was $19.1 \%$ for placebo, $21.6 \%$ for 1 year of sorafenib, and $24 \%$ for 3 years of sorafenib. Table 3

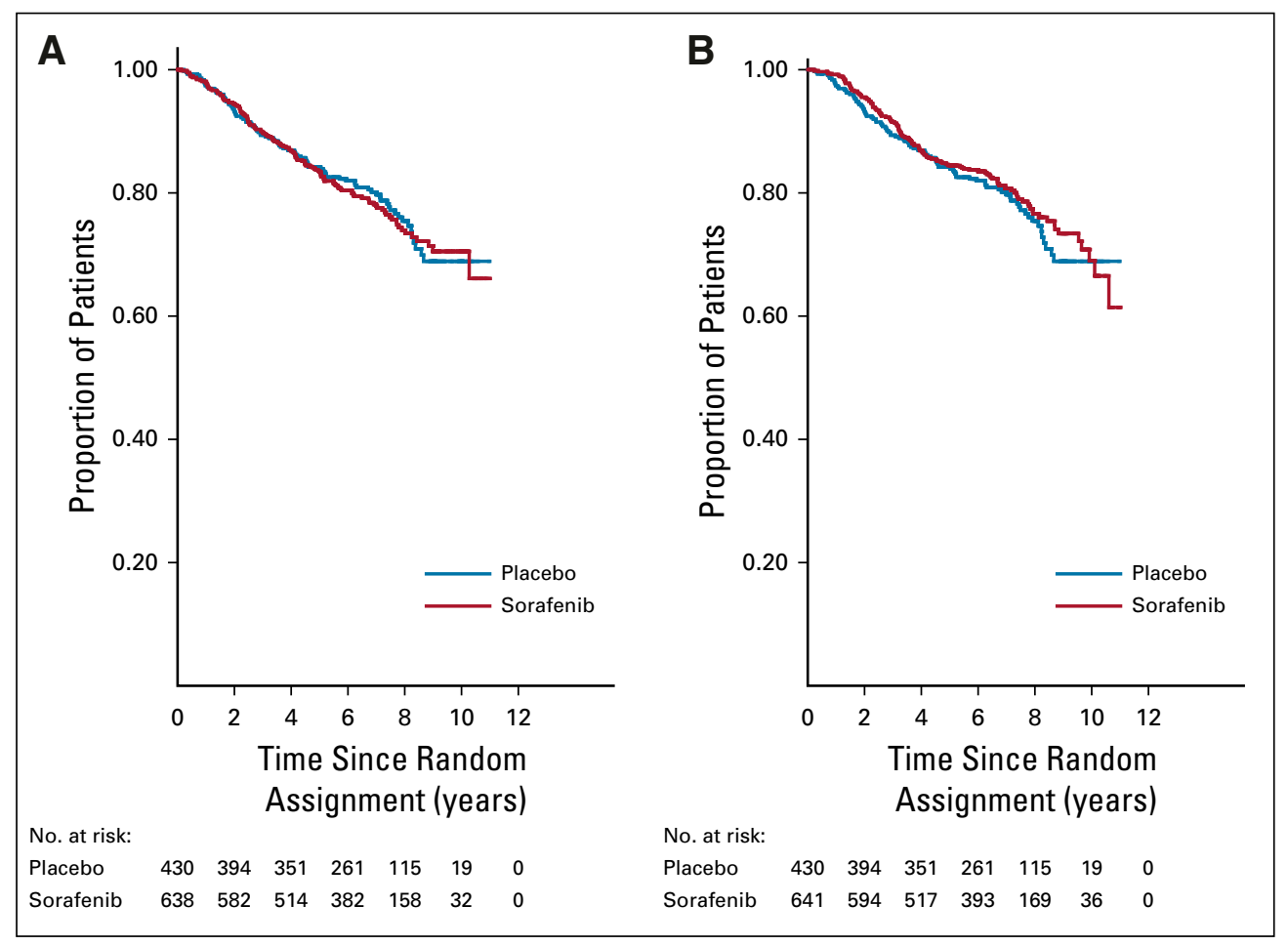

FIG 3. Overall survival in patients randomly assigned to (A) 3 years of sorafenib versus placebo and (B) 1 year of sorafenib versus placebo. The figures have been truncated at 11 years. 
TABLE 3. Patients in the Safety Population Who Experienced AEs and Serious AEs and the Worst Grade AE Reported

AE

Placebo

Any grade $A E$ (at least one), No. (\%)

Grade $\geq 3 A E$ (at least one), No. (\%)

At least one serious $A E$

Adverse event, $\%^{a}$

Rash

\begin{tabular}{l}
\hline Rash \\
\hline Any grade \\
\hline Grade 3 \\
\hline Grade 4 \\
\hline Diarrhea \\
\hline Any grade \\
\hline Grade 3 \\
\hline Grade 4
\end{tabular}

\begin{tabular}{l}
\hline Hand-foot syndrome \\
\hline Any grade \\
\hline Grade 3 \\
\hline Grade 4 \\
\hline Fatigue
\end{tabular}

\begin{tabular}{|c|c|c|c|}
\hline Any grade & 60 & 74 & 74 \\
\hline Grade 3 & 2 & 4 & 4 \\
\hline Grade 4 & 0 & 0 & 0 \\
\hline \multicolumn{4}{|l|}{ Nausea } \\
\hline Any grade & 26 & 34 & 30 \\
\hline Grade 3 & 1 & 1 & 0 \\
\hline Grade 4 & 0 & 0 & 0 \\
\hline \multicolumn{4}{|l|}{ Hypertension } \\
\hline Any grade & 48 & 60 & 64 \\
\hline Grade 3 & 20 & 26 & 24 \\
\hline Grade 4 & 0 & 0 & 0 \\
\hline \multicolumn{4}{|l|}{ Alopecia } \\
\hline Any grade & 12 & 54 & 49 \\
\hline Grade 3 & 0 & 0 & 0 \\
\hline Grade 4 & 0 & 0 & 0 \\
\hline \multicolumn{4}{|l|}{ Other } \\
\hline Any grade & 87 & 88 & 89 \\
\hline Grade 3 & 9 & 12 & 17 \\
\hline Grade 4 & 1 & 1 & 2 \\
\hline
\end{tabular}

Abbreviation: AE, adverse event.

apercentages are based on the number of patients in the safety population in each arm.

provides a breakdown of AEs and SAEs by arm. Worst grade of AEs reported in each of the three arms is also listed in Table 3. Notable toxicities were hand-foot skin reactions and hypertension.

\section{Other Secondary Outcome Measures}

Results from the analyses of both MFS and RCC-specific survival time are provided in the Appendix (Appendix

1 Year of Sorafenib

3 Years of Sorafenib $608(99.2)$ $392(63.9)$ $147(24)$

$366(58.6)$

$135(21.6)$

71

10

0

0

$\begin{array}{ll}61 & 64 \\ 6 & 6 \\ 0 & 0\end{array}$

\begin{tabular}{rr}
79 & 77 \\
24 & 24 \\
0 & 0 \\
\hline
\end{tabular}


TABLE 4. Reasons Patients Stopped Treatment in the SORCE Trial

$\%$ of Patients

\begin{tabular}{lccc} 
& Placebo & 1 Year of Sorafenib & 3ears of Sorafenib \\
\hline Protocol treatment completed & 55 & 33 & 25 \\
\hline Disease progression & 24 & 15 & 13 \\
\hline Excessive toxicity & 4 & 30 & 34 \\
\hline Patient refusal & 8 & 14 & 15 \\
\hline Clinical decision/other medical condition & 3 & 6 & 9 \\
\hline New primary cancer & 1 & 1 & 1 \\
\hline Death & 0.2 & 0.3 & 0.2 \\
\hline Other (error/administrative reasons) & 1 & 1 & 2 \\
\hline Missing & 2 & 1 & 1
\end{tabular}

participants ( $\mathrm{n}=1,485,87 \%$ ) started treatment on an initial dose of $400 \mathrm{mg}$ once daily for the first 3 weeks, which could be extended for longer if required. Dose reductions in the event of significant toxicity and subsequent reescalation on resolution were permitted. As in the other adjuvant TKI trials in patients with RCC and despite the permitted dose modifications, many participants did not complete their assigned protocol treatment, even in the placebo arm. Approximately half of participants had withdrawn from treatment by the end of the first year in both treatment arms (Appendix Table A7, online only). We present time to discontinuation or termination of treatment in Appendix Figure A5 (online only). Appendix Figure A6 (online only) presents months on treatment against total pill count for each treatment arm, graphically illustrating that patients found it difficult to comply with protocol treatment and many patients ended treatment prematurely.

Median number of months on treatment was 35.4 months (IQR, 11.4-35.9 months) for placebo, 11.7 months (IQR, 1.9-35.6 months) for 1 year of sorafenib, and 10.6 months (IQR, 2.3-35.2 months) for 3 years of sorafenib. The reduced starting dose, although introduced quite early on in the trial, had little overall effect on the median (or mean) number of months on treatment (Appendix Table A8, online only). Reasons for stopping treatment are listed in Table 4.

\section{Treatment on Recurrence}

The number of participants in each arm who received additional systemic treatment after progression was similar in each of the arms (Appendix Table A9, online only).

\section{DISCUSSION}

SORCE was an international, phase III trial investigating sorafenib, an oral multikinase inhibitor, in patients with resected RCC at intermediate or high risk of recurrence and including all histologic subtypes. We observed no difference in DFS for either 3 years or 1 year of sorafenib compared with placebo in the overall trial population, the Leibovich high-risk participants, or participants with clear cell RCC. Similarly, we showed no difference in duration of OS between participants who received 3 years or 1 year of sorafenib versus placebo. We did not observe proportional hazards; we found an apparent separation between the curves, but it does not support further investigation when the overall results are so definitive.

Our results are in line with those from the ASSURE trial, which showed no benefit of 1 year of sunitinib or sorafenib compared with placebo (DFS: HR, 1.02 [97.5\% Cl, 0.85 to 1.23 ] and 0.97 [97.5\% Cl, 0.80 to 1.17 ] for sunitinib and sorafenib, respectively). ${ }^{8}$ They are also in line with the PROTECT and ATLAS trial results. ${ }^{7,9}$ S-TRAC was the only study to show a modest DFS benefit with 1 year of sunitinib (HR, 0.76; 95\% Cl, 0.59 to $0.98 ; P=.03$ ) but only when DFS events were subject to blinded independent central review; no improvement in OS was observed. ${ }^{10,11}$ Appendix Table A10 (online only) summarizes the inclusion criteria and risk scores used in these trials.

Drug toxicity and the resultant reticence of participants to stay on treatment were observed in all of the adjuvant TKI trials; SORCE was no different. We amended the SORCE protocol after $<18$ months of accrual. The TMG had noticed that many patients were stopping treatment as a result of toxicity (particularly skin rash). Our IDMC encouraged an amendment when they reviewed the unblinded data in October 2008. We submitted an amended protocol for ethics and regulatory approval in November 2008, and the change was implemented at sites in January 2009.

Despite reducing the initial dose for the first 3 weeks, allowing flexibility in the requirement for escalation to full standard dose, and encouraging dose reductions to mitigate toxicity, only $33 \%$ and $25 \%$ of SORCE participants completed 1 and 3 years of protocol treatment, respectively. Approximately half of participants had withdrawn from treatment by the end of the first year in both treatment arms, with excessive toxicity and patient refusal cited as the dominant reasons for stopping. In SORCE, 
grade $\geq 3$ AEs were reported in $59 \%-64 \%$ of participants on treatment, which is comparable to findings in other TKI trials. Hand-foot skin reaction and hypertension caused the most grade 3 events in the 1 - and 3 -year cohorts, which we were unable to mitigate with our dosing strategy. Ultimately, the high $\mathrm{AE}$ rates leading to dose reductions and early stoppages, seen across all adjuvant TKI trials, are likely to have affected the efficacy of TKIs in this setting. An exploratory analysis conducted as part of a systematic review and pooled analysis of trial data from SORCE, ASSURE, and PROTECT suggests that participants who started on full dose may have an improved DFS ( $\mathrm{HR}_{\text {random }}, 0.83 ; 95 \% \mathrm{Cl}$, 0.73 to $0.95 ; P=.005) .{ }^{13}$ However, this is exactly the limiting factor because full-dose treatment was only achieved in a minority of participants who took part in any of the VEGF-targeted adjuvant trials.

The risk-benefit profile of additional treatment is an essential consideration in patients receiving treatment and experiencing toxicity in the adjuvant setting without overt metastatic disease. The significant toxicity observed with TKI monotherapy, despite pragmatic dose reductions, together with lack of evidence of a survival benefit, fundamentally undermines the use of TKIs in the adjuvant treatment of RCC. The results from our patient preferences for an adjuvant sorafenib substudy support this observation. Treatment duration and the toxicity patients experienced were both important determinants of patients' preferences for adjuvant sorafenib. A typical participant who had been treated with adjuvant sorafenib judged that to warrant continuing it for 3 years, a median survival gain of an additional 9-12 months would be required, above and beyond the 9-12 months required to make the initial 1 year of adjuvant therapy worthwhile. ${ }^{21}$

In SORCE, imaging alternated between chest $x$-ray and contrast CT of the chest and abdomen every 3 months

\footnotetext{
AFFILIATIONS

${ }^{1}$ Department of Oncology, Cambridge University Hospitals National Health Service (NHS) Foundation Trust, Cambridge, United Kingdom ${ }^{2}$ Medical Research Council Clinical Trials Unit at University College London (UCL), Institute of Clinical Trials and Methodology, London, United Kingdom

${ }^{3}$ Monash University and Eastern Health, Box Hill, Victoria, Australia ${ }^{4}$ National Health and Medical Research Council Clinical Trials Centre, Central Clinical School, Department of Medicine, University of Sydney, Sydney, New South Wales, Australia

${ }^{5}$ Institut Gustave Roussy, Villejuif, France

${ }^{6}$ The Royal Marsden Hospital, London, United Kingdom

${ }^{7}$ Royal Free London NHS Foundation Trust UCL, Division of Surgery and Interventional Science, London, United Kingdom

${ }^{8}$ Netherlands Cancer Institute, Amsterdam, the Netherlands

${ }^{9}$ Department of Development and Regeneration, Urogenital, Abdominal, and Plastic Surgery, University Hospitals Leuven, Leuven, Belgium

${ }^{10}$ University of Sheffield, Academic Unit of Clinical Oncology, Weston Park Cancer Centre, Sheffield, United Kingdom

${ }^{11}$ Urology Research Unit, Department of Urology, Herlev/Gentofte Hospital, Herlev, Denmark
}

during treatment. After completion of treatment, participants had chest $x$-rays only every 6 months until year 5 and then annually until year 10 , but with advice to confirm clinical signs of recurrence via CT or x-ray or a positive biopsy. This was different from the other TKI trials, which used CT scans or magnetic resonance imaging throughout. Of our 654 disease recurrence events, 547 were reported on CT scan, only nine were reported on chest x-ray, and 77 were reported using mixed modalities or biopsies (information is missing for 21 participants). Method of assessment was similar across arms.

Effective adjuvant therapy for patients who have had their primary renal cancer removed by surgery remains an unmet clinical need. The international infrastructure developed to conduct SORCE over the years has paved the way for our current adjuvant trial RAMPART (ClinicalTrials.gov identifier: NCT03288532), a University College London-sponsored multiarm, multistage platform trial investigating single-agent durvalumab (anti-programmed death ligand-1) and durvalumab in combination with tremelimumab (anti-cytotoxic T-lymphocyte-associated protein 4). Numerous other adjuvant trials investigating immune checkpoint inhibitors either as monotherapies or in combination are ongoing and will report over the coming years.

The results from SORCE unequivocally confirm that sorafenib should not be used as adjuvant therapy for patients with resected RCC at intermediate or high risk of relapse. We observed no DFS or OS benefit for up to 3 years of sorafenib treatment in this patient group, yet participants experienced a range of treatment-associated toxicities. Active surveillance remains the global standard of care for patients at intermediate or high risk of recurrence after nephrectomy and is the appropriate control arm of our current international adjuvant RCC trial, RAMPART.

\footnotetext{
${ }^{12}$ Beth Israel Deaconess Medical Center-IMIM Research Lab, Boston, MA ${ }^{13}$ Pharmacy Department, Weston Park Hospital, Sheffield, United Kingdom

${ }^{14}$ Department of Surgery, University of Cambridge, Addenbrooke's Hospital, Cambridge, United Kingdom

${ }^{15}$ Velindre Cancer Centre, Cardiff, United Kingdom

${ }^{16}$ Academic Unit of Clinical Oncology, Weston Park Hospital, University of Sheffield, Sheffield, United Kingdom

${ }^{17}$ Institute of Cancer and Pathology, St James's University Hospital, University of Leeds, Leeds, United Kingdom

${ }^{18}$ Northern Centre for Cancer Care, Freeman Hospital, Newcastle upon Tyne, United Kingdom

${ }^{19}$ Mount Vernon Cancer Centre, Northwood, United Kingdom
}

\section{DISCLAIMER}

Cancer Research UK and Bayer had no role in the study design; in the collection, analysis, and interpretation of data; in the writing of the report; or in the decision to submit the article for publication. Staff funded by the Medical Research Council and University College London contributed to study design, data collection, data analysis, data interpretation, and writing of this report. 


\section{CORRESPONDING AUTHOR}

Tim Eisen, MB BChir, PhD, Department of Oncology, Cambridge University Hospitals NHS Foundation Trust, Box 193 (R4),

Addenbrooke's Hospital, Cambridge Biomedical Campus, Hill's Road, Cambridge CB2 OQQ, United Kingdom; e-mail: tgqe2@

medschl.cam.ac.uk.

\section{PRIOR PRESENTATION}

Presented at the European Society of Medical Oncology 2019 Congress, Barcelona, Spain, September 27-October 1, 2019.

\section{SUPPORT}

Supported by a clinical trials grant from Cancer Research UK; an educational research grant from Bayer, which also provided free sorafenib and the matched placebo and covered the cost of both the randomization system and the linked drug supply management system; the Medical Research Council; and University College London. The Australian and New Zealand Urogenital and Prostate (ANZUP) Cancer Trials Group is supported by the Australian Government through Cancer Australia. ANZUP received funding support for the SORCE trial from Bayer Australia. I.D.D. is supported by an Australian National Health and Medical Research Council Practitioner Fellowship (Grant No. APP1102604).

\section{CLINICAL TRIAL INFORMATION}

ISRCTN38934710 (SORCE), EUDRACT 2006-006079-19 (SORCE), CTA 00316/0222/001-0001 (SORCE), NCT00492258 (SORCE).

\section{AUTHORS' DISCLOSURES OF POTENTIAL CONFLICTS OF INTEREST}

Disclosures provided by the authors are available with this article at DO https://doi.org/10.1200/JC0.20.01800.

\section{AUTHOR CONTRIBUTIONS}

Conception and design: Tim Eisen, Alastair W.S. Ritchie, Ian D. Davis, Martin R. Stockler, Bernard Escudier, Barry Hancock, Joaquim Bellmunt, Elizabeth Hodgkinson, Janet Brown, Angela Meade

Administrative support: Benjamin Smith, Martin R. Stockler, Gregers G. Hermann, Angela Meade

Provision of study materials or patients: Tim Eisen, Ian D. Davis, Laurence Albiges, Martin R. Stockler, Bernard Escudier, James Larkin, Axel Bex, Gregers G. Hermann, Joaquim Bellmunt, Jim Barber, Janet Brown, Rhona McMenemin, Paul Nathan, Lisa M. Pickering

Collection and assembly of data: Alastair W.S. Ritchie, Benjamin Smith, Rick Kaplan, Ian D. Davis, Martin R. Stockler, Laurence Albiges, Steven
Joniau, Gregers G. Hermann, Joaquim Bellmunt, Jim Barber, Janet Brown, Rhona McMenemin, Angela Meade

Data analysis and interpretation: Tim Eisen, Eleni Frangou, Bhavna Oza, Alastair W.S. Ritchie, Rick Kaplan, Ian D. Davis, Martin R. Stockler, Laurence Albiges, Bernard Escudier, James Larkin, Axel Bex, Steven Joniau, Joaquim Bellmunt, Grant D. Stewart, Janet Brown, Paul Nathan, Lisa M. Pickering, Mahesh K.B. Parmar, Angela Meade

Manuscript writing: All authors

Final approval of manuscript: All authors

Accountable for all aspects of the work: All authors

\section{DEDICATION}

We dedicate this article to Pat Hanlon and Martin Gore. Pat was our patient and public involvement representative on the trial management group, who sadly died in January 2020. Martin was a friend and mentor to many of us as well as being an excellent medical oncologist who constantly shouted encouragement from the sidelines. Both Martin and Pat had a huge commitment to kidney cancer research, and we miss them very much.

\section{ACKNOWLEDGMENT}

We thank our 1,711 participants for their willingness to take part in research to inform future generations. Through ongoing clinical trials, we continue to strive for better outcomes for patients with resected renal cell carcinoma. We thank all of the staff at each of our 147 sites (Appendix, online only). We thank our colleagues at Bayer; Centre Leon Berard, France; European Organisation for Research and Treatment of Cancer (EORTC); ADKNOMA Research, Spain; Australian and New Zealand Urogenital and Prostate Cancer Trials Group, University of Sydney/ National Health and Medical Research Council of Australia; Institute of Cancer Research, University of Leeds, Leeds Teaching Hospitals National Health Service Trust; INC Research; and Catalent and Rigshospitalet, Denmark, for their collaboration and support. We thank Anouk Neven, statistician at the EORTC Headquarters, Brussels, Belgium, for her contribution to this article. We also acknowledge the following people and their roles over the course of the trial: chief investigator: Tim Eisen; renal program lead: Rick Kaplan; project lead: Angela Meade; statisticians: Eleni Frangou, Louise Choo, Clare Griffin, Patrick Royston, and Max Parmar; trial managers: Ben Smith, Anna Griffiths, Beth May, and Tahera Hussain; project managers: Rahela Choudhury, Nicola Joffe, Claire Amos, and Clare Shakeshaft; trial physicians: Bhavna Oza and Alastair Ritchie; data managers: Nat Thorogood, Andy Welland, Adam Gregory, Catrin Jones, and Will Cragg; and database programmers: Brendan Mauger.

\section{REFERENCES}

1. Bray F, Ferlay J, Soerjomataram I, et al: Global cancer statistics 2018: GLOBOCAN estimates of incidence and mortality worldwide for 36 cancers in 185 countries. CA Cancer J Clin 68:394-424, 2018

2. National Cancer Institute Surveillance, Epidemiology, and End Results Program: Cancer Stat Facts: Kidney and renal pelvis cancer. https://seer.cancer.gov/ statfacts/html/kidrp.html

3. Blick C, Ritchie AWS, Eisen T, et al: Improving outcomes in high-risk, nonmetastatic renal cancer: New data and ongoing trials. Nat Rev Urol 14:753-759, 2017

4. Escudier B, Eisen T, Stadler WM, et al: Sorafenib for treatment of renal cell carcinoma: Final efficacy and safety results of the phase III treatment approaches in renal cancer global evaluation trial. J Clin Oncol 27:3312-3318, 2009

5. Garnick MB: Preserving the sanctity of overall survival for drugs approved on the basis of progression-free survival: Tivozanib as a case study. J Clin Oncol 31: 3746-3748, 2013

6. Motzer RJ, Porta C, Vogelzang NJ, et al: Dovitinib versus sorafenib for third-line targeted treatment of patients with metastatic renal cell carcinoma: An openlabel, randomised phase 3 trial. Lancet Oncol 15:286-296, 2014

7. Gross-Goupil M, Kwon TG, Eto M, et al: Axitinib versus placebo as an adjuvant treatment of renal cell carcinoma: Results from the phase III, randomized ATLAS trial. Ann Oncol 29:2371-2378, 2018

8. Haas NB, Manola J, Uzzo RG, et al: Adjuvant sunitinib or sorafenib for high-risk, non-metastatic renal-cell carcinoma (ECOG-ACRIN E2805): A double-blind, placebo-controlled, randomised, phase 3 trial. Lancet 387:2008-2016, 2016 
9. Motzer RJ, Haas NB, Donskov F, et al: Randomized phase III trial of adjuvant pazopanib versus placebo after nephrectomy in patients with localized or locally advanced renal cell carcinoma. J Clin Oncol 35:3916-3923, 2017

10. Ravaud A, Motzer RJ, Pandha HS, et al: Adjuvant sunitinib in high-risk renal-cell carcinoma after nephrectomy. N Engl J Med 375:2246-2254, 2016

11. Motzer RJ, Ravaud A, Patard J-J, et al: Adjuvant sunitinib for high-risk renal cell carcinoma after nephrectomy: Subgroup analyses and updated overall survival results. Eur Urol 73:62-68, 2018

12. Bex A, Albiges L, Ljungberg B, et al: Updated European Association of Urology Guidelines regarding adjuvant therapy for renal cell carcinoma. Eur Urol 71: 719-722, 2017

13. Sun M, Marconi L, Eisen T, et al: Adjuvant vascular endothelial growth factor-targeted therapy in renal cell carcinoma: A systematic review and pooled analysis. Eur Urol 74:611-620, 2018

14. Leibovich BC, Blute ML, Cheville JC, et al: Prediction of progression after radical nephrectomy for patients with clear cell renal cell carcinoma: A stratification tool for prospective clinical trials. Cancer 97:1663-1671, 2003

15. Cancer Research UK: SORCE Trial Protocol, 2017. https://www.ctu.mrc.ac.uk/media/1297/sorce-protocol-v70-jul-2017.pdf

16. Barthel FM-S, Royston P, Babiker A: A menu-driven facility for complex sample size calculation in randomized controlled trials with a survival or a binary outcome: Update. Stata J 5:123-129, 2005

17. Royston P, Parmar MKB: The use of restricted mean survival time to estimate the treatment effect in randomized clinical trials when the proportional hazards assumption is in doubt. Stat Med 30:2409-2421, 2011

18. Royston P, Parmar MKB: Restricted mean survival time: An alternative to the hazard ratio for the design and analysis of randomized trials with a time-to-event outcome. BMC Med Res Methodol 13:152, 2013

19. Henrion M, Frampton M, Scelo G, et al: Common variation at 2q22.3 (ZEB2) influences the risk of renal cancer. Hum Mol Genet 22:825-831, 2013

20. Henrion MYR, Purdue MP, Scelo G, et al: Common variation at 1q24.1 (ALDH9A1) is a potential risk factor for renal cancer. PLoS One 10:e0122589, 2015

21. Blinman PL, Davis ID, Martin A, et al: Patients' preferences for adjuvant sorafenib after resection of renal cell carcinoma in the SORCE trial: What makes it worthwhile? Ann Oncol 29:370-376, 2018

22. Fairfax BP, Pratap S, Roberts ISD, et al: Fatal case of sorafenib-associated idiosyncratic hepatotoxicity in the adjuvant treatment of a patient with renal cell carcinoma. BMC Cancer 12:590, 2012 
The following represents disclosure information provided by authors of this manuscript. All relationships are considered compensated unless otherwise noted. Relationships are self-held unless noted. I = Immediate Family Member, Inst = My Institution. Relationships may not relate to the subject matter of this manuscript. For more information about ASCO's conflict of interest policy, please refer to www.asco.org/rwc or ascopubs.org/jco/authors/author-center.

Open Payments is a public database containing information reported by companies about payments made to US-licensed physicians (Open Payments).

\section{Tim Eisen}

Employment: AstraZeneca, Roche

Leadership: AstraZeneca, Roche

Stock and Other Ownership Interests: AstraZeneca, AstraZeneca (I)

Honoraria: EUSA

Consulting or Advisory Role: EUSA

Research Funding: Bayer (Inst), Pfizer (Inst), AstraZeneca (Inst)

Travel, Accommodations, Expenses: AstraZeneca, Roche

Other Relationship: Macmillan Cancer Support, Kidney Cancer UK

Richard Kaplan

Research Funding: AstraZeneca (Inst)

Ian D. Davis

Research Funding: Astellas Pharma (Inst), Pfizer (Inst), Genentech (Inst), MSD Oncology (Inst), AstraZeneca (Inst), Janssen Oncology (Inst), Eisai (Inst), Bayer (Inst), Amgen (Inst), Bristol Myers Squibb (Inst), Movember Foundation (Inst), Exelixis (Inst), Ipsen (Inst), Medivation (Inst)

Patents, Royalties, Other Intellectual Property: International Patent Application No: PCT/US2004/032147 (NY-ESO-1) through Ludwig Institute for Cancer Research

\section{Martin R. Stockler}

Research Funding: Astellas Pharma (Inst), Celgene (Inst), Bayer (Inst), Bionomics (Inst), Medivation (Inst), Sanofi (Inst), Pfizer (Inst), AstraZeneca (Inst), Bristol Myers Squibb (Inst), Roche (Inst), Amgen (Inst), Merck Sharp \& Dohme (Inst), Tilray (Inst)

Travel, Accommodations, Expenses: Medivation/Pfizer

\section{Laurence Albiges}

Consulting or Advisory Role: Novartis (Inst), Amgen (Inst), Bristol Myers Squibb (Inst), Ipsen (Inst), Roche (Inst), Novartis (Inst), Pfizer (Inst), Astellas Pharma (Inst), Merck (Inst), MSD (Inst), AstraZeneca (Inst), Exelixis (Inst), Corvus Pharmaceuticals (Inst), Peloton Therapeutics (Inst)

Research Funding: Bristol Myers Squibb (Inst)

Travel, Accommodations, Expenses: Bristol Myers Squibb, MSD

Bernard Escudie

Honoraria: Pfizer, Novartis, Bristol Myers Squibb, Ipsen, Genentech, EUSA Pharma, Oncorena

Consulting or Advisory Role: Novartis, Pfizer, Bristol Myers Squibb, Ipsen, EUSA Pharma, AVEO Pharmaceuticals, Genentech

Research Funding: Bristol Myers Squibb France (Inst)

Travel, Accommodations, Expenses: Bristol Myers Squibb, Pfizer, Genentech, Ipsen, MSD

\section{James Larkin}

Honoraria: Eisai, Bristol Myers Squibb, MSD, GlaxoSmithKline, Pfizer, Novartis Genentech, Pierre Fabre, EUSA Pharma, Achilles Therapeutics, AstraZeneca, Boston Biomedical, Ipsen, Imugene, Incyte, iOnctura, Merck Serono, Nektar, Vitaccess, Kymab, Secarna

Consulting or Advisory Role: Eisai, Bristol Myers Squibb, MSD, GlaxoSmithKline, Pfizer, Novartis, Genentech, Pierre Fabre, EUSA Pharma, Achilles Therapeutics, AstraZeneca, Boston Biomedical, Ipsen, Imugene, Incyte, iOnctura, Merck Serono, Nektar, Vitaccess, Secarna, Kymab

Research Funding: Pfizer (Inst), Novartis (Inst), MSD (Inst), Bristol Myers Squibb (Inst), Achilles Therapeutics (Inst), Roche (Inst), Nektar (Inst), Covance (Inst), Immunocore (Inst), AVEO Pharmaceuticals (Inst)

Travel, Accommodations, Expenses: Bristol Myers Squibb, Pfizer, Novartis, Genentech, AstraZeneca, Boston Biomedical, Incyte, GlaxoSmithKline, Pierre Fabre, Merck Serono

\section{Axel Bex}

Consulting or Advisory Role: Pfizer (Inst), Novartis (Inst), Bristol Myers Squibb (Inst), Ipsen (Inst), Eisai (Inst), Genentech (Inst)

Speakers' Bureau: Pfizer, Novartis, Bristol Myers Squibb

Research Funding: Pfizer (Inst)

Steven Joniau

Consulting or Advisory Role: Janssen, AstraZeneca, Bayer, Astellas Pharma Speakers' Bureau: Astellas Pharma, Janssen, Ipsen

Research Funding: Janssen (Inst), Astellas (Inst), Ipsen (Inst), Bayer (Inst) Ferring (Inst)

Travel, Accommodations, Expenses: Janssen, Ipsen, Astellas Pharma

Joaquim Bellmunt

Stock and Other Ownership Interests: Rainier

Honoraria: UpToDate

Consulting or Advisory Role: Pierre Fabre, Astellas Pharma, Pfizer, Merck, Genentech, Novartis, AstraZeneca/Medlmmune, Bristol Myers Squibb

Research Funding: Millennium (Inst), Sanofi (Inst), Pfizer/EMD Serono (Inst) Travel, Accommodations, Expenses: Pfizer, MSD Oncology, Ipsen

\section{Grant D. Stewart}

Honoraria: Pfizer, Merck, EUSA Pharma

Consulting or Advisory Role: CMR Surgical

Research Funding: Pfizer, AstraZeneca

Janet Brown

Consulting or Advisory Role: Novartis, Bayer, Amgen, Ipsen, MSD Oncology Research Funding: Amgen (Inst), Bayer (Inst)

Travel, Accommodations, Expenses: Ipsen, MSD Oncology, Amgen, Novartis, Bayer

\section{Rhona McMenemin}

Honoraria: Janssen Oncology, EUSA Pharma

Consulting or Advisory Role: Ipsen, EUSA Pharma

Speakers' Bureau: EUSA Pharma

Travel, Accommodations, Expenses: EUSA Pharma, Janssen Oncology

Paul Nathan

Consulting or Advisory Role: AstraZeneca, Bristol Myers Squibb, MSD,

Immunocore, Pfizer, Pierre Fabre, Novartis, GlaxoSmithKline, Ipsen, 4SC, Merck Speakers' Bureau: Bristol Myers Squibb, Novartis, MSD, Merck

Travel, Accommodations, Expenses: Bristol Myers Squibb, MSD

Lisa M. Pickering

Consulting or Advisory Role: Pfizer, Ipsen, Bristol Myers Squibb, Eisai, MSD Oncology

Speakers' Bureau: Pfizer, Bristol Myers Squibb

Honoraria: Pfizer, EUSA Pharma, Ipsen, MSD Oncology, Bristol Myers Squibb Consulting or Advisory Role: Pfizer, Astellas Pharma, EUSA Pharma, MSD

Oncology, Bristol Myers Squibb

Research Funding: Pierre Fabre

Travel, Accommodations, Expenses: Bristol Myers Squibb, Ipsen

Angela Meade

Research Funding: AstraZeneca (Inst)

No other potential conflicts of interest were reported. 


\section{Subgroup Analyses}

Power to analyze whether up to 3 years of sorafenib increases disease-free survival compared with placebo was calculated based on event rates estimated from published data (STRAC, ASSURE, and ATLAS). With 506 participants with a high-risk Leibovich score in arms $A$ and $C$ and assuming an event rate of $53 \%$, we had $65 \%$ power to detect a hazard ratio (HR) of 0.75 at the $5 \%$ two-sided significance level. Similarly, with 898 participants with clear cell histology in arms $\mathrm{A}$ and $\mathrm{C}$ and assuming an event rate of $47 \%$, we had $84 \%$ power to detect an HR of 0.75 at the $5 \%$ two-sided significance level.

\section{Participating Institutions}

The following institutions participated in the study (with lead investigator at each site): Velindre Hospital, Dr Jim Barber; Addenbrooke's Hospital, Prof Tim Eisen; St James University Hospital, Dr Janet Brown; Freeman Hospital, Dr Rhona McMenemin; Mount Vernon Hospital, Dr Paul Nathan; Weston Park Hospital, Dr Omar Din; Cheltenham General Hospital, Dr David Farrugia; Royal Marsden Hospital, Prof Martin Gore; James Cook University Hospital, Dr Alison Humphreys; Leicester General Hospital, Dr Subramanian Vasanthan; Beatson West of Scotland Cancer Centre, Dr Rob Jones; Clatterbridge Centre for Oncology, Dr Richard Griffiths; Queen Alexandra Hospital, Dr Joanna Gale; Royal Derby Hospital, Dr Prabir Chakraborti; Royal Free Hospital, Dr Ekaterini Boleti; Christie Hospital, Dr Tom Waddell; Kent and Canterbury Hospital, Dr Natasha Mithal; Royal Perth Hospital, Dr Simon Troon; Bristol Haematology and Oncology Centre, Dr Amit Bahl; Norfolk and Norwich University Hospital, Dr Rob Wade; Birmingham City Hospital, Dr Daniel Ford; Lincoln County Hospital, Dr Miguel Panades; Castle Hill Hospital, Dr Anthony Maraveyas; St Bartholomews Hospital, Dr Jonathon Shamash; Rigshospitalet University Hospital, Dr Gregers Hermann; University Hospital Coventry and Warwickshire, Dr Jane Worlding; Universitaire Ziekenhuizen Leuven, Prof Hein van Poppel; Derriford Hospital, Dr Martin Highley; Austin Hospital, Prof lan Davis; Centre Hospitalier Universitaire de Besançon, Dr Antoine Thiery-Vuillemin; Institut Gustave-Roussy, Prof Bernard Escudier; Ipswich Hospital, Dr Christopher Scrase; Royal Stoke University Hospital, Dr Fawzi Adab; Royal Shrewsbury Hospital, Dr Narayanan Srihari; Royal Devon and Exeter Hospital, Dr Rajaguru Srinivasan; Southend University Hospital, Dr Imtiaz Ahmed; Northampton General Hospital, Dr Mario Uccello; Royal Bournemouth Hospital, Dr Tom Geldart; Scunthorpe General Hospital, Dr Sanjay Dixit; Erasmus MC, Dr Willem Harm Jan Kruit; Centre Alexis Vautrin, Dr Lionnel Geoffrois; Institut Paoli Calmettes, Dr Gwenaelle Gravis; Glan Clwyd Hospital, Dr Carey Macdonald-Smith; Prince of Wales Hospital, Dr Elizabeth Hovey; Southampton General Hospital, Dr Matthew Wheater; St George's Hospital, Dr Lisa Pickering; Maidstone Hospital, Dr Sharon Beesley; Wexham Park Hospital, Dr Nicola Dallas; Westmead Hospital, Prof Howard Gurney; Churchill Hospital, Prof Andrew Protheroe; Dorset County Hospital, Stephen Andrews; Nottingham
University Hospital, Prof Poulam Patel; Weston General Hospital, Dr Serena Hilman; Royal Brisbane \& Women's Hospital, Dr Jeffrey Goh; Darent Valley Hospital, Sanjeev Madaan; Diana Princess of Wales Hospital, Dr Sanjay Dixit; King's Mill Hospital, Dr Santhanam Sundar; Fremantle Hospital, Dr Phillip Claringbold; Canberra Hospital, Dr Desmond Yip; Royal Prince Alfred Hospital, Dr Michelle Harrison; Basildon Hospital, Dr Awais Jalil; Royal Berkshire Hospital, Dr Helen O'Donnell; Torbay District General Hospital, Dr Anna Lydon; Institut de Cancerologie de la Loire, Dr Aline Guillot; Aberdeen Royal Infirmary, Dr Graham MacDonald; Belfast City Hospital, Dr Seamus McAleer; Charing Cross Hospital, Dr Naveed Sarwar; Poole Hospital, Dr Tom Geldart; Queen's Hospital, Dr Mike Smith-Howell; Southmead Hospital, Raj Persad; Worcestershire Royal Hospital, Dr Lisa Capaldi; The Alfred, Dr Sanjeev Gill; Onze Lieve Vrouwziekenhuis, Dr Paul Carpentier; Hôpital Saint-Andre, Dr Alain Ravaud; Centre Hospitalier Universitaire de Rouen, Prof Christian Pfister; Great Western Hospital, Dr Omar Khan; Guy's Hospital, Dr Simon Chowdhury; Pilgrim Hospital, Dr Miguel Panades; Queen Elizabeth Queen Mother Hospital, Dr Natasha Mithal; Salisbury District Hospital, Dr Adityanarayan Bhatnagar; Warwick Hospital, Dr Andrew Chan; Flinders Medical Centre, Dr Ganessan Kichenadasse; Royal Adelaide Hospital, Dr Nimit Singhal; Concord Hospital, Prof Martin Stockler; University Hospital Gent, Prof Sylvie Rottey; Institut Claudius Regaud, Dr Christine Chevreau; Salford Royal Hospital, Prof Noel Clarke; William Harvey Hospital, Dr Natasha Mithal; Box Hill, Dr Joseph McKendrick; Royal North Shore Hospital, Dr Nick Pavlakis; Hôpital Nord, Dr Marjorie Baciuchka; Broomfield Hospital, Dr Gopalakrishnan Srinivasan; South Tyneside District Hospital, Dr Ashraf Azzabi; Western General Hospital, Dr Duncan McLaren; Wycombe Hospital, Dr Prabir Chakraborti; Ysbyty Gwynedd, Dr Anna Mullard; Hospital Ramon y Cajal, Dr Maria Lopez; James Paget Hospital, Dr Rob Wade; Stafford General Hospital, Dr Rajanee Bhana; Sunderland Royal Hospital, Dr Ashraf Azzabi; Sir Charles Gairdner Hospital, Dr Siobhan Ng; Port Macquarie Base Hospital, Dr Stephen Begbie; Radboud University Nijmegen Medical Centre, Prof Peter Mulders; Centre Jean Perrin, Dr Hakim Mahammedi; Centre Hospitalier Universitaire de Limoges, Dr Aurelien Descazeaud; Instituto Valenciano Oncología, Dr Miguel Climent; Alexandra Hospital, Dr Lisa Capaldi; Conquest Hospital, Dr Kathryn Lees; Musgrove Park Hospital, Dr John Graham; Queen Elizabeth Hospital, Dr Anjali Zarkar; Royal United Hospital, Dr Mark Beresford; Border, Dr Craig Underhill; Peninsula Oncology Centre, Dr Vinod Ganju; Centre Léon Bérard, Prof Sylvie Negrier; Centre Paul Papin, Dr Remy Delva; Hospital del Mar, Dr Joaquim Bellmunt; Essex County Hospital, Dr Dakshinamoorthy Muthukumar; Scarborough General Hospital, Simon Hawkyard; St Richard's Hospital, James Hicks; Royal Hobart Hospital, Dr Louise Nott; Jules Bordet Institute, Dr Thierry Gil; Fundació Puigvert, Dr Joan Palou; Whipps Cross University Hospital, Dr Thomas Powles; Yeovil District Hospital, Tim Porter; Centre George-Francois Leclerc, Dr Sylvain Ladoire; Clinique Valdegour, Dr Eric Legouffe; Val d'Aurelle, Dr Diego Tosi; Centre Hospitalier Aix-en-Provence, Dr Sophie Nahon; Clinica Universitaria Navarra, Dr Jose Perez-Gracia. 


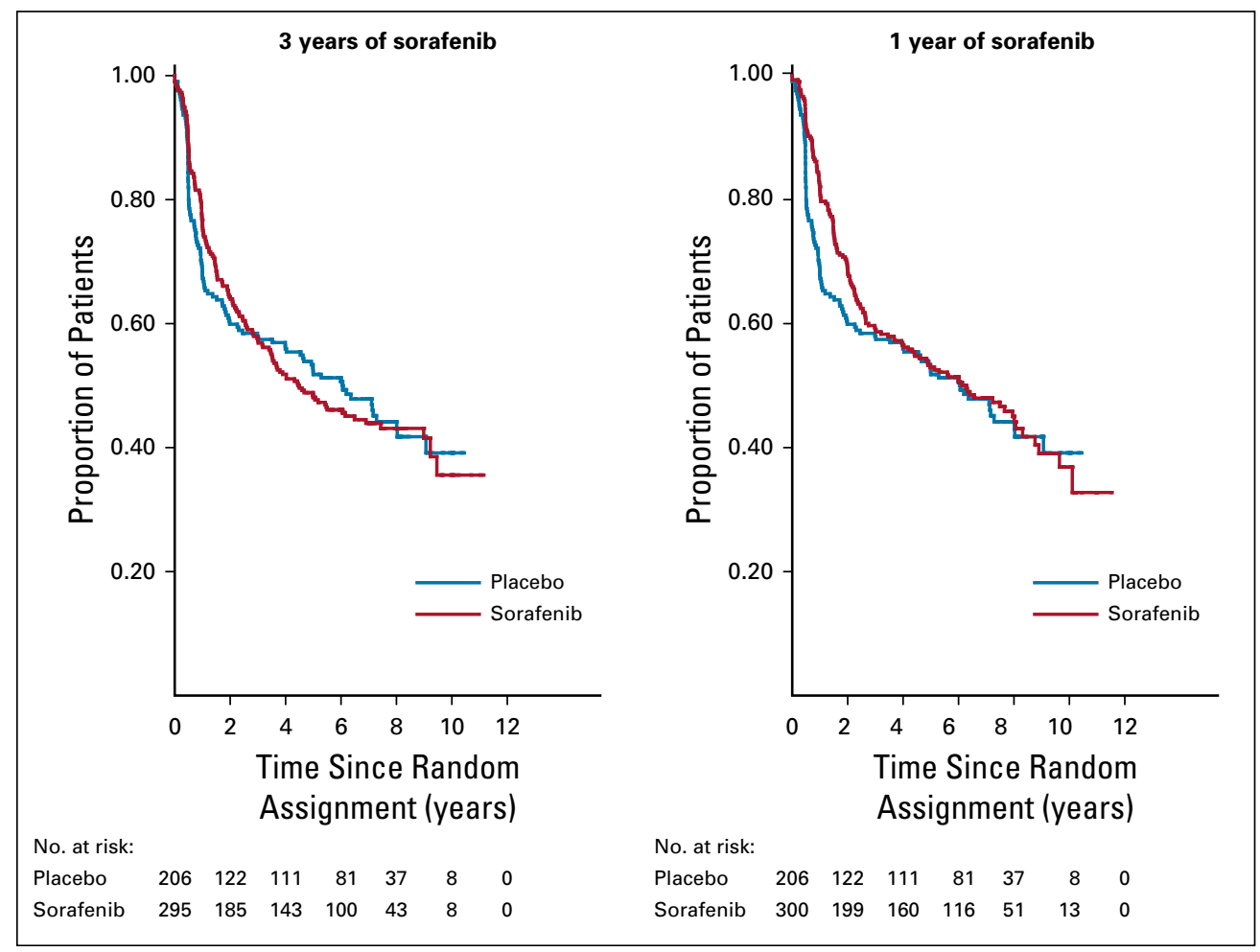

FIG A1. Kaplan-Meier curves of the prespecified and prepowered disease-free survival analyses in Leibovich high-risk patients. 


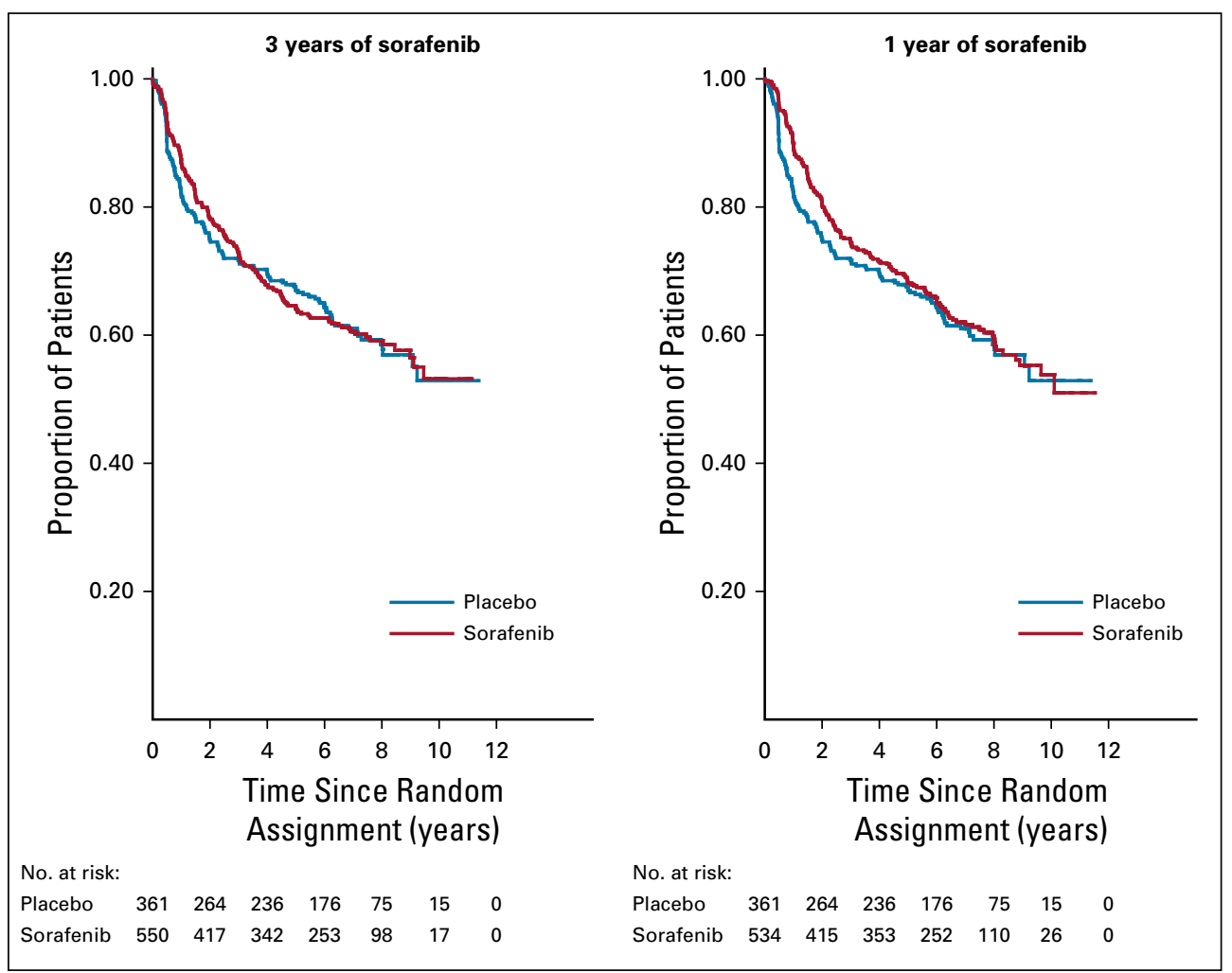

FIG A2. Kaplan-Meier curves of the prespecified and prepowered disease-free survival analyses in patients with clear cell renal cell carcinoma. 


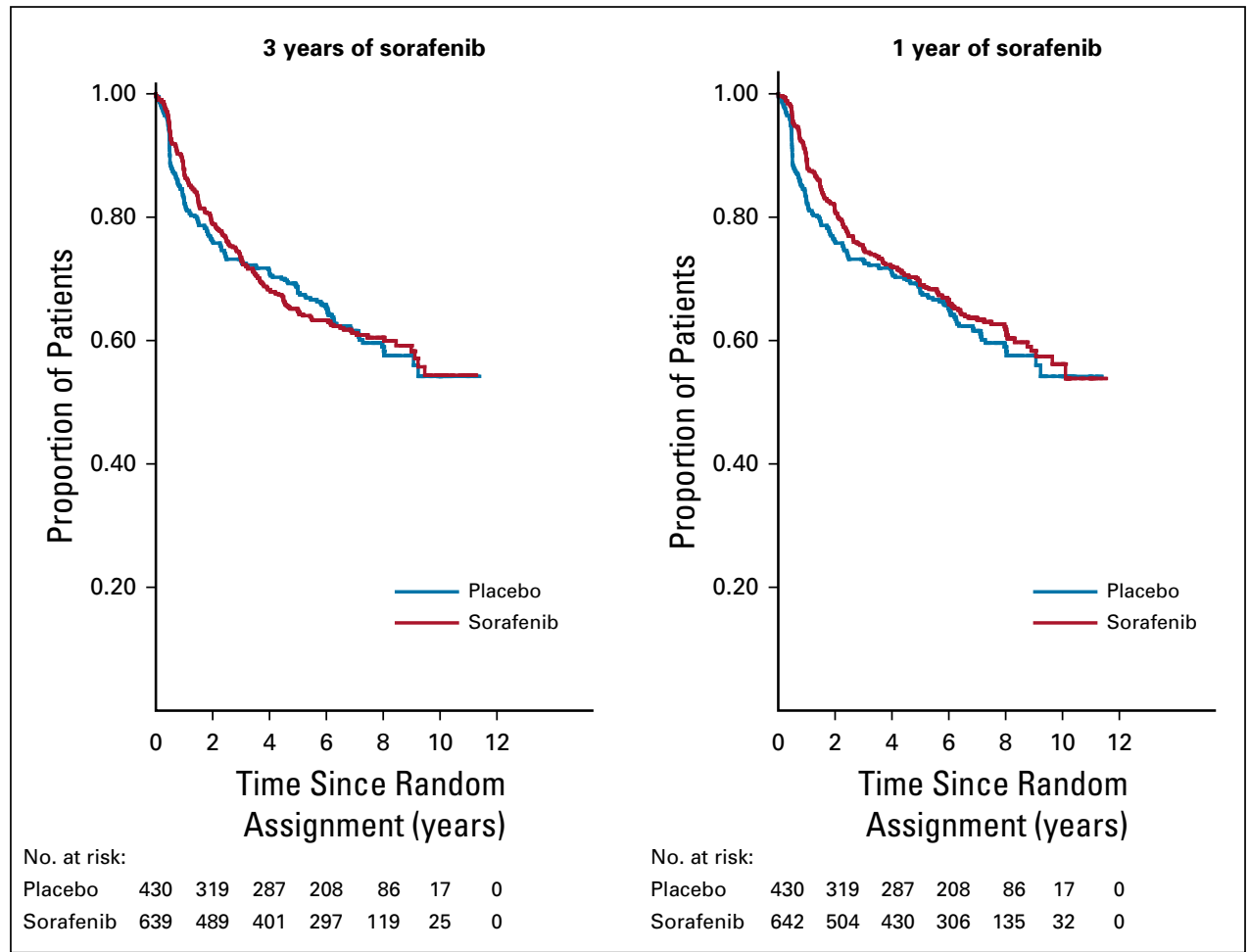

FIG A3. Kaplan-Meier curves for metastasis-free survival. 


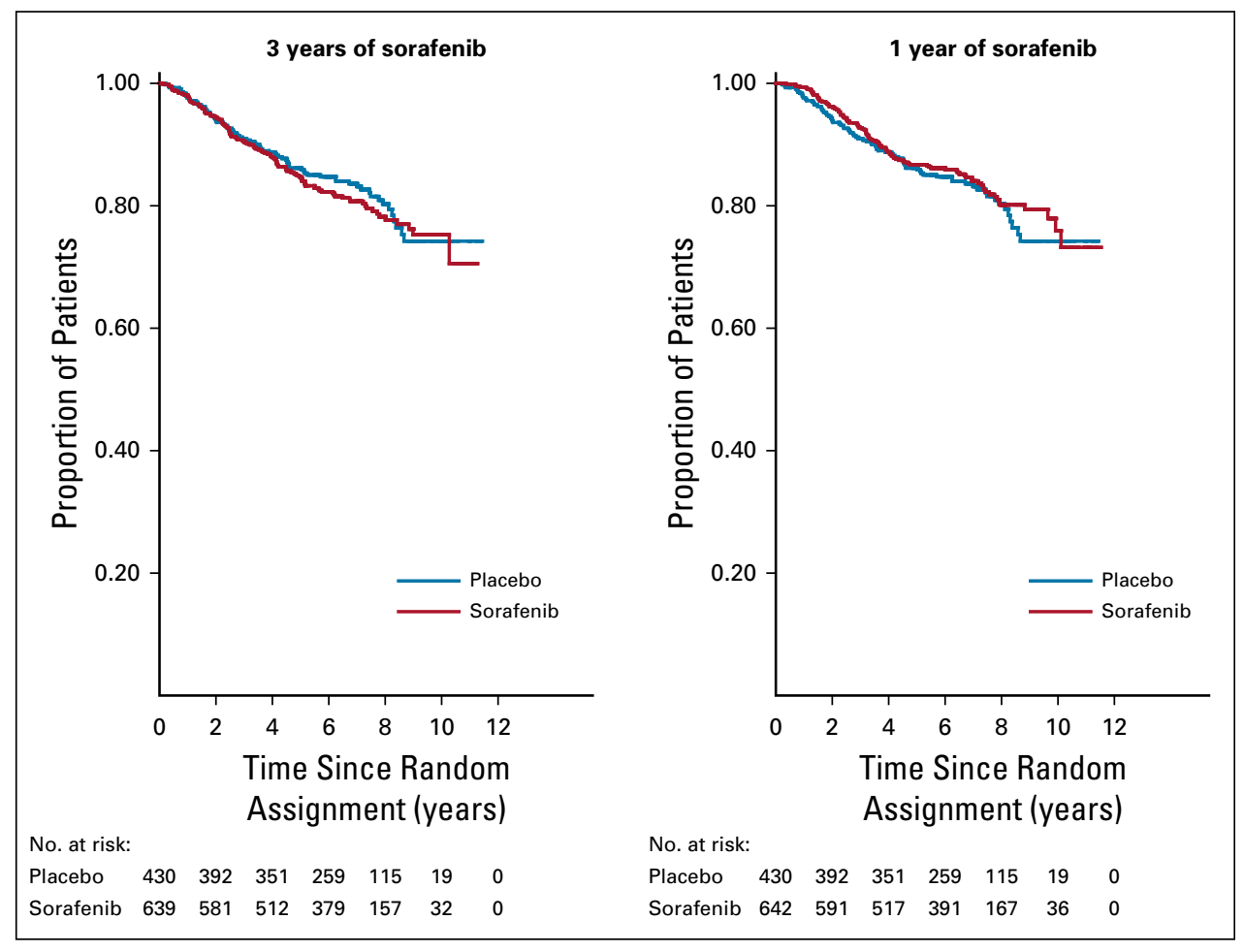

FIG A4. Kaplan-Meier curves for renal cell carcinoma (RCC)-specific survival. 


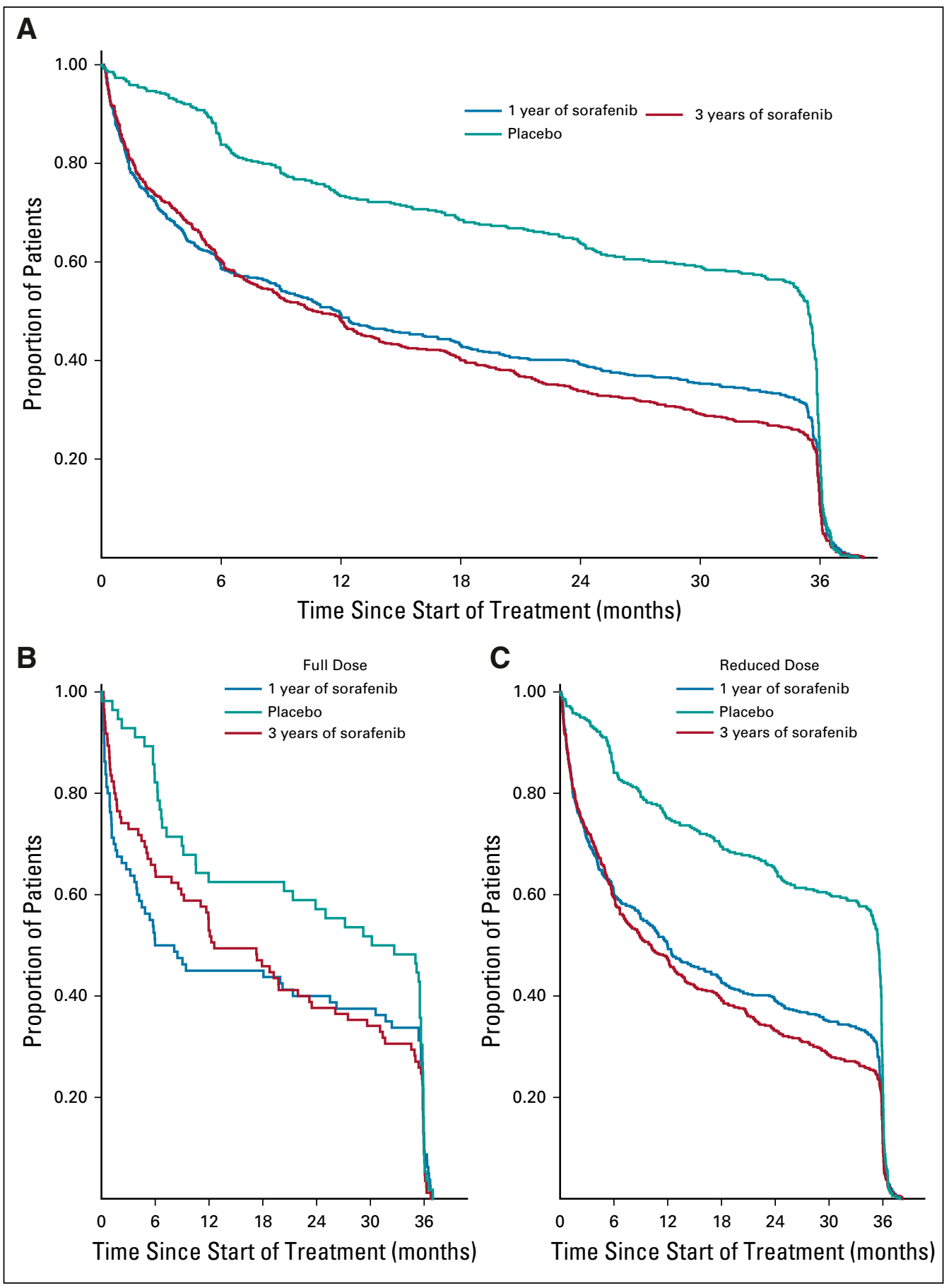

FIG A5. Time to discontinuation or end of treatment by arm, (A) overall and by starting dose: (B) full dose and (C) reduced dose. 


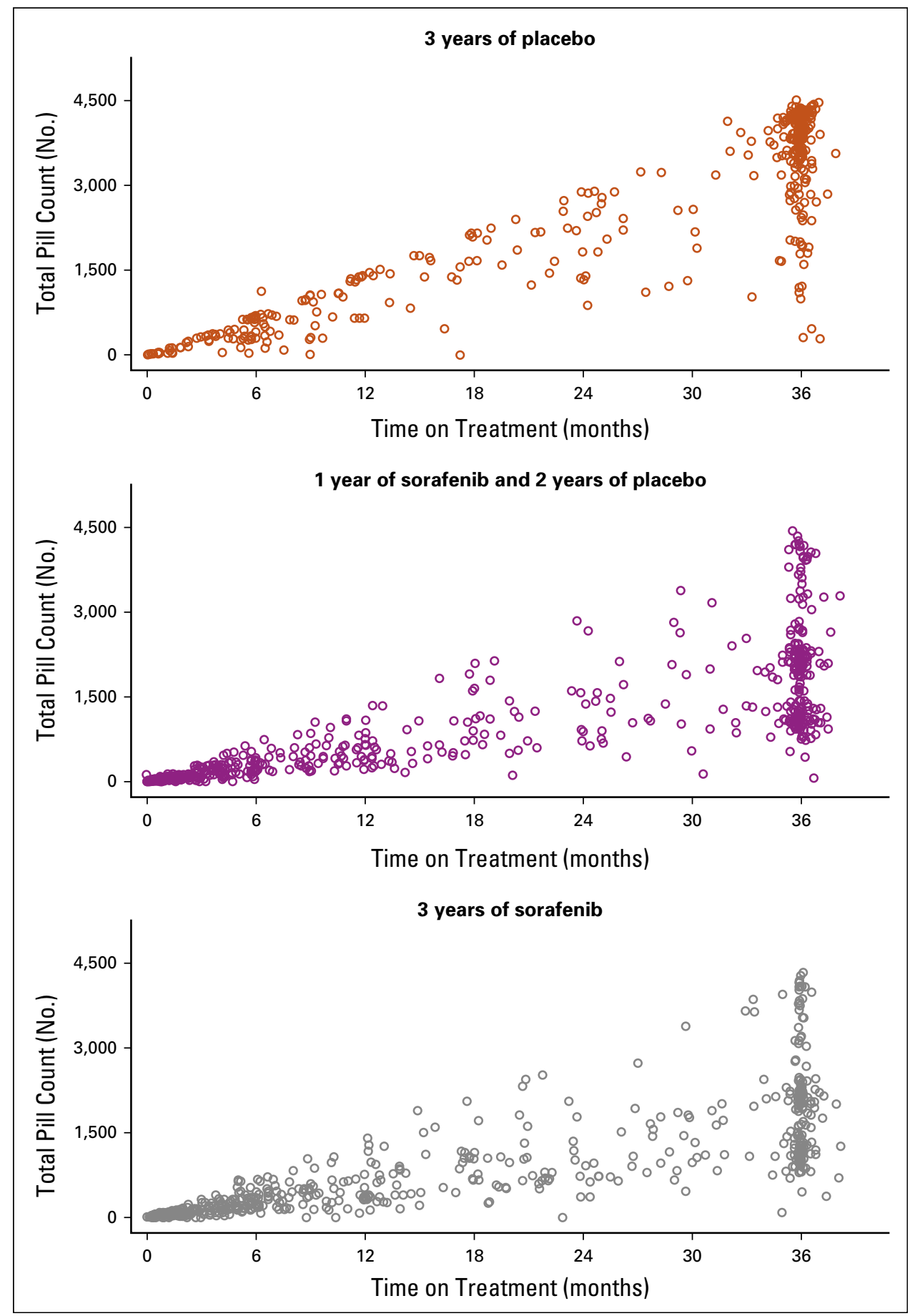

FIG A6. Months on treatment versus total pill count taken per participant in each of the arms. For patients who reached 36 months on treatment, total pill count varied significantly. 
TABLE A1. Leibovich Risk Score Components and Risk Group

Categories

Feature

Score

\begin{tabular}{ll}
\hline Pathologic T category of primary tumor & \\
\hline pT1a & 0 \\
\hline pT1b & 2 \\
\hline pT2 & 3 \\
\hline pT3a-4 & 4 \\
\hline
\end{tabular}

Regional lymph node status

\begin{tabular}{lc}
\hline $\mathrm{pNx}$ or pNO & 0 \\
\hline $\mathrm{pN} 1-2$ & 2 \\
\hline Tumor size, cm & \\
\hline$<10$ & 0 \\
\hline$\geq 10$ & 1 \\
\hline Nuclear grade & 0 \\
\hline 1 or 2 & 1 \\
\hline 3 & 3 \\
\hline 4 & \\
\hline Histologic tumor necrosis & 0 \\
\hline No & 1
\end{tabular}

NOTE. Leibovich score is the sum of the score given for each feature: low risk, score of 0-2; intermediate risk, score of 3-5; and high risk, score of $\geq 6$.

TABLE A2. Summary of Other Causes of Death by Treatment Arm

\section{No. of Patients}

Cause

Placebo

1 Year of Sorafenib

3 Years of Sorafenib

\begin{tabular}{llll}
\hline Cardiovascular & 2 & 5 & 3 \\
\hline Drug reaction (not trial drug) & 1 & 0 & 0 \\
\hline Infection & 3 & 6 & 4 \\
\hline Neurologic disease & 0 & 0 & 1 \\
\hline Other malignancy & 4 & 9 & 2 \\
\hline Respiratory & 2 & 0 & 3 \\
\hline Surgical complication & 0 & 0 & 1 \\
\hline Trauma & 0 & 0 & 1 \\
\hline Unknown & 5 & 4 & 5 \\
\hline Total & 17 & 24 & 20
\end{tabular}


TABLE A3. Summary of DFS Results in Leibovich High-Risk Patients, in Patients With Clear Cell RCC, and in the Modified DFS Population

DFS

RMST

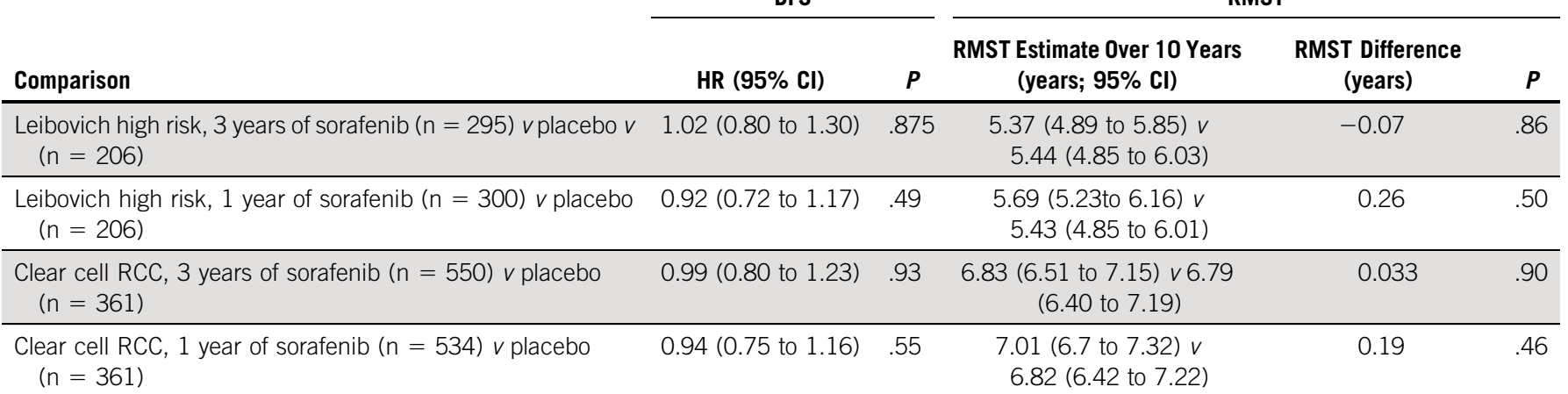

NOTE. In Leibovich high-risk patients, we observed no difference in DFS between patients randomly assigned to 3 years of sorafenib versus placebo or to 1 year of sorafenib versus placebo; nonproportional hazards were observed $(P=.01$ and $P<.0001$, respectively). The RMST estimates over 10 years are shown in the table. In patients with clear cell RCC, we also observed no difference in DFS between patients randomly assigned to 3 years of sorafenib versus placebo or to 1 year of sorafenib versus placebo; nonproportional hazards were observed $(P=.08$ and $P<.0001$, respectively). The RMST estimates over 10 years are shown in the table.

Abbreviations: DFS, disease-free survival; HR, hazard ratio; RCC, renal cell carcinoma; RMST, restricted mean survival time.

TABLE A4. Summary of Modified DFS Results

\section{Modified DFS ${ }^{2}$}

$\begin{array}{cccc} & & \text { RMST Estimate Over } 10 \text { Years (years; } \\ \text { HR }(95 \% \mathrm{Cl}) & P & 95 \% \mathrm{Cl})\end{array}$

Comparison

$95 \% \mathrm{Cl}$

3 years of sorafenib $(n=639) v$ placebo $(n=430) \quad 1.02(0.85$ to 1.23$) \quad .83 \quad 6.43(6.13$ to 6.84$) v 6.47(6.11$ to 6.84$)$

1 year of sorafenib $(n=642) v$ placebo $(n=430) \quad 0.96(0.80$ to 1.15$) \quad 64 \quad 6.57(6.27$ to 6.86$) v 6.44(6.07$ to 6.81$)$

NOTE. The following modified definition of DFS was explored to align with the definition used in the ASSURE and S-TRAC trials: time from randomization to first evidence of recurrence, development of any second primary cancer, or death from any cause.

Abbreviations: DFS, disease-free survival; HR, hazard ratio; RMST, restricted mean survival time.

\section{Metastasis-Free Survival \\ Metastasis-Free Survival}

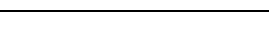

Comparison

HR $(95 \% \mathrm{Cl})$

3 years of sorafenib $(n=639) v$ placebo $(n=430)$

$1.00(0.82$ to 1.22$)$

1 year of sorafenib $(n=642) v$ placebo $(n=430) \quad 0.90(0.74$ to 1.10$)$

Abbreviations: HR, hazard ratio; RMST, restricted mean survival time.

TABLE A6. Renal Cell Carcinoma-Specific Survival Analysis

Renal Cell

Carcinoma-Specific

Survival

RMST

Comparison

HR $(95 \% \mathrm{Cl}) \quad \boldsymbol{P}$ $95 \% \mathrm{Cl})$

\begin{tabular}{|c|c|c|c|c|c|}
\hline 3 years of sorafenib $(n=639) v$ placebo $(n=430)$ & 1.12 (0.85 to 1.50$)$ & .42 & 8.57 (8.35 to 8.79$)$ v 8.71 (8.45 to 8.96$)$ & -0.14 & .42 \\
\hline 1 year of sorafenib $(n=642) v$ pla & 0.91 (0.68 to 1.22$)$ & .52 & $8.81(8.61$ to 9.02$) v 8.68(8.42$ to 8.94$)$ & 0.13 & \\
\hline
\end{tabular}

Abbreviations: HR, hazard ratio; RMST, restricted mean survival time.

(C) 2020 by American Society of Clinical Oncology

Downloaded from ascopubs.org by UCL Library Services on October 19, 2020 from 193.060.238.225 Copyright (C 2020 American Society of Clinical Oncology. All rights reserved. 
TABLE A7. Time on Trial Before Stopping Treatment

No. of Patients (\%)

\begin{tabular}{lccc}
\cline { 2 - 4 } Months on Treatment & Placebo & 1 Year of Sorafenib Plus 2 Years of Placebo & 3 Years of Sorafenib \\
\hline$\leq 1$ & $11(3)$ & $98(15)$ & $88(14)$ \\
\hline $1-2$ & $8(2)$ & $58(9)$ & $55(9)$ \\
\hline $2-3$ & $5(1)$ & $31(5)$ & $25(4)$ \\
\hline $3-6$ & $43(10)$ & $71(11)$ & $76(12)$ \\
\hline $6-12$ & $43(10)$ & $59(9)$ & $74(12)$ \\
\hline $12-18$ & $20(5)$ & $37(6)$ & $49(8)$ \\
\hline $18-24$ & $19(4)$ & $25(4)$ & $39(6)$ \\
\hline $24-30$ & $20(5)$ & $24(4)$ & $29(5)$ \\
\hline $30-36+$ & $244(57)$ & $218(34)$ & $178(28)$
\end{tabular}

NOTE. Percentages are based on the number of randomly assigned patients in each arm.

TABLE A8. Time on Treatment

\begin{tabular}{lccc}
\hline Overall & & & \\
\hline Median time on treatment, months (IQR) & $35.42(11.43-35.94)$ & $11.19(2.00-12.16)$ & $10.71(2.27-35.29)$ \\
\hline Mean time on treatment, months (SD) & $25.63(13.24)$ & $7.78(5.21)$ & 16.08 (14.35) \\
\hline Full dose & & & \\
\hline No. of patients & 57 & 84 & 85 \\
\hline Median time on treatment, months (IQR) & $31.41(6.72-35.86)$ & $5.98(1.12-12.19)$ & $12.58(2.20-35.65)$ \\
\hline Mean time on treatment, months (SD) & $23.31(14.04)$ & $7.20(5.56)$ & $17.69(14.54)$ \\
\hline Reduced dose & 373 & 558 & $10.15(2.33-35.19)$ \\
\hline No. of patients & $35.48(12.22-35.98)$ & $11.27(2.30-12.16)$ & $15.82(14.32)$
\end{tabular}

Abbreviations: IQR, interquartile range; SD, standard deviation. 
TABLE A9. Summary of First Posttrial Treatment

No. of Patients (\%)

\begin{tabular}{lcccc}
\cline { 2 - 5 } Treatment & Placebo & $\mathbf{1}$ Year of Sorafenib Plus $\mathbf{2}$ Years of Placebo & 3 Years of Sorafenib & Total \\
\hline Sunitinib & $34(8)$ & $54(8)$ & $64(10)$ & $152(9)$ \\
\hline Pazopanib & $19(4)$ & $40(6)$ & $45(7)$ & $104(6)$ \\
\hline Sorafenib & $14(3)$ & $8(1)$ & $2(0.3)$ & $24(1)$ \\
\hline Interferon- $\alpha$, interleukin-2, fluorouracil & $3(1)$ & $6(1)$ & $3(0.5)$ & $12(0.7)$ \\
\hline Other & $12(3)$ & $19(3)$ & $16(3)$ & $47(3)$ \\
\hline Total & $82(20)$ & $127(20)$ & $130(20)$ & $339(20)$
\end{tabular}

NOTE. Percentages are based on the number of randomly assigned patients in each arm. 
TABLE A10. Characteristics, Inclusion Criteria, and Risk Scores of Completed Adjuvant Trials for Kidney Cancer

\begin{tabular}{|c|c|c|c|c|c|}
\hline Characteristic & $\begin{array}{l}\text { ASSURE (ClinicalTrials.gov } \\
\text { identifier: NCT00326898) }\end{array}$ & S-TRAC & PROTECT & ATLAS & SORCE \\
\hline No. of patients & 1,943 & 615 & 1,538 & 724 & 1,711 \\
\hline Treatment arms & $\begin{array}{l}\text { Sunitinib or sorafenib } v \\
\text { placebo }\end{array}$ & Sunitinib $v$ placebo & $\begin{array}{c}\text { Pazopanib } v \\
\text { placebo }\end{array}$ & Axitinib $v$ placebo & $\begin{array}{l}\text { Sorafenib for } 1 \text { year or } \\
\text { sorafenib for } 3 \text { years } v \\
\text { placebo }\end{array}$ \\
\hline $\begin{array}{l}\text { Duration of } \\
\text { treatment, } \\
\text { years }\end{array}$ & 1 & 1 & 1 & 3 & 3 \\
\hline Inclusion criteria & $\begin{array}{l}\text { TNM } 2002 \text { staging: } \\
\text { pT1b, G3-4, NO or pNx, M0 } \\
\text { pT2, G any, NO or pNx, M0 } \\
\text { pT3, G any, NO or pNx, MO } \\
\text { pT4, G any, NO or pNx, M0 } \\
\text { pT any, G any, N+ (fully } \\
\text { resected), MO }\end{array}$ & $\begin{array}{l}\text { TNM } 2002 \text { staging: } \\
\text { pT2, G3-4, NO or pNx, } \\
\text { MO } \\
\text { pT3, G any, NO or pNx, } \\
\text { MO } \\
\text { pT4, G any, NO or pNx, } \\
\text { MO } \\
\text { pT any, G any, N+ (fully } \\
\text { resected), MO }\end{array}$ & $\begin{array}{l}\text { TNM } 2010 \\
\text { staging: } \\
\text { pT2, G3-4, N0 or } \\
\text { pNx, M0 } \\
\text { pT3, G any, NO or } \\
\text { pNx, MO } \\
\text { pT4, G any, NO or } \\
\text { pNx, MO } \\
\text { pT any, G any, N1, } \\
\text { MO }\end{array}$ & $\begin{array}{l}\text { TNM } 2010 \text { staging: } \\
\text { pT2, G any, pNO or pNx, } \\
\text { MO } \\
\text { pT3, G any, pNO or pNx, } \\
\text { MO } \\
\text { pT4, G any, pNO or pNx, } \\
\text { MO } \\
\text { Any pT, G any, pN1, MO }\end{array}$ & $\begin{array}{l}\text { TNM } 2002 \text { staging: } \\
\text { PT any, N1-2, M0 as per } \\
\text { Leibovich score of 3-11 } \\
\text { (see Appendix Table A1 } \\
\text { for Leibovich score } \\
\text { breakdown) }\end{array}$ \\
\hline
\end{tabular}

\begin{tabular}{|c|c|c|c|c|c|}
\hline $\begin{array}{l}\text { Microscopic } \\
\text { disease }\end{array}$ & $\begin{array}{l}\text { M0 patients with evidence of } \\
\text { microscopic disease (R1) } \\
\text { are acceptable }\end{array}$ & $\begin{array}{l}\text { M0 patients with } \\
\text { evidence of } \\
\text { microscopic disease } \\
\text { (R1) are acceptable }\end{array}$ & & $\begin{array}{l}\text { Patients must have no } \\
\text { evidence of } \\
\text { macroscopic residual } \\
\text { disease or metastatic } \\
\text { disease }\end{array}$ & $\begin{array}{l}\text { M0 patients with evidence } \\
\text { of microscopic disease } \\
\text { (R1) are acceptable }\end{array}$ \\
\hline Histology & Clear cell and non-clear cell & Clear cell predominant & $\begin{array}{l}\text { Clear cell } \\
\text { predominant } \\
(>50 \%)\end{array}$ & $\begin{array}{l}\text { Clear cell predominant (> } \\
50 \% \text { ) }\end{array}$ & $\begin{array}{l}\text { Clear cell and non-clear } \\
\text { cell }\end{array}$ \\
\hline Risk score & $\begin{array}{l}\text { Modified UISS intermediate } \\
\text { high to very high }\end{array}$ & Modified UISS high risk & $\begin{array}{l}\text { SSIGN } \\
\text { intermediate to } \\
\text { high risk }\end{array}$ & TNM and Fuhrman grade & $\begin{array}{l}\text { Leibovich intermediate to } \\
\text { high }\end{array}$ \\
\hline
\end{tabular}

Abbreviations: ECOG, Eastern Cooperative Oncology Group; SSIGN, stage, size, grade and necrosis; UISS, University of California Los Angeles Integrated Staging System. 